\title{
Life-time expression of the proteins peroxiredoxin, beta-synuclein, PARK7/DJ-1, and stathmin in the primary visual and primary somatosensory cortices in rats
}

\author{
Michael R. R. Böhm ${ }^{1,2 *}$, Harutyun Melkonyan ${ }^{1}$ and Solon Thanos ${ }^{1}$ \\ Institute of Experimental Ophthalmology and DFG-Center of Excellence Cells in Motion (CiM), area C.4, School of Medicine, Westfalian-Wilhelms-University of \\ Münster, Münster, Germany \\ ${ }^{2}$ Department of Ophthalmology, St. Franziskus Hospital Münster, Münster, Germany
}

\section{Edited by:}

Nicolás Cuenca, University of Alicante, Spain

\section{Reviewed by:}

Alino Martinez-Marcos, Universidad de Castilla, Spain

Guy Elston, Centre for Cognitive

Neuroscience, Australia

*Correspondence:

Michael R. R. Böhm, Institute of Experimental Ophthalmology and DFG-Center of Excellence Cells in Motion (CiM), area C.4, School of Medicine,

Westfalian-Wilhelms-University of Münster, Albert-Schweitzer-Campus 1, D15, 48149 Münster, Germany e-mail:michael.boehm@

ukmuenster.de
Four distinct proteins are regulated in the aging neuroretina and may be regulated in the cerebral cortex, too: peroxiredoxin, beta-synuclein, PARK[Parkinson diseaselautosomal recessive, early onset)]7/DJ-1, and Stathmin. Thus, we performed a comparative analysis of these proteins in the the primary somatosensory cortex (S1) and primary visual cortex (V1) in rats, in order to detect putative common development-, maturation- and age-related changes. The expressions of peroxiredoxin, beta-synuclein, PARKIParkinson disease (autosomal recessive, early onset)]7/DJ-1, and Stathmin were compared in the newborn, juvenile, adult, and aged S1 and V1. Western blot (WB), quantitative reverse-transcription polymerase chain reaction (qRT-PCR), and immunohistochemistry (IHC) analyses were employed to determine whether the changes identified by proteomics were verifiable at the cellular and molecular levels. All of the proteins were detected in both of the investigated cortical areas. Changes in the expressions of the four proteins were found throughout the life-time of the rats. Peroxiredoxin expression remained unchanged over life-time. Beta-Synuclein expression was massively increased up to the adult stage of life in both the S1 and V1. PARK[Parkinson disease (autosomal recessive, early onset)]7/DJ-1 exhibited a massive up-regulation in both the S1 and V1 at all ages. Stathmin expression was massively down regulated after the neonatal period in both the S1 and V1. The detected protein alterations were analogous to their retinal profiles. This study is the first to provide evidence that peroxiredoxin, beta-synuclein, PARKIParkinson disease (autosomal recessive, early onset)]7/DJ-1, and Stathmin are associated with postnatal maturation and aging in both the S1 and V1 of rats. These changes may indicate their involvement in key functional pathways and may account for the onset or progression of age-related pathologies.

Keywords: aging, cortex, peroxiredoxin, beta-synuclein, PARK7/DJ-1, stathmin

\section{INTRODUCTION}

Cerebral maturation and aging is characterized by stereotypical structural and neurophysiological changes that result in marked variations in the dendritic morphology of pyramidal neurons in different cortical areas (Elston, 2002; Jacobs and Scheibel, 2002). Topologically, the cortical development of the visual and prefrontal cortex exhibit different time frames during the process of generating the dense network of pyramidal cells (Elston and Fujita, 2014). Moreover, there is a significant loss of synapses in the post-exhuberant postnatal cortex (Huttenlocher, 1990; Bourgeois and Rakic, 1993; Rakic et al., 1994; Huttenlocher and Dabholkar, 1997). These regional differences in pyramidal cell structure and synaptic density patterns may be the determinants of cortical function and may be associated with the functional and physiological aspects of learning processes for each cortical region (Elston, 2003; Spruston, 2008). The extent and branching complexity of dendrites, as well as the number and density of the spines on those dendrites, increases from the primary sensory area to higher-order processing areas, such as the prefrontal cortex (Elston, 2000; Jacobs et al., 2001; Elston et al., 2006a, 2009; Bianchi et al., 2013). In addition to neurons, neuroglia cells and microglia constitute the most numerous cell population in the mammalian brain (Mori and Leblond, 1969; Ling, 1976; Imamoto and Leblond, 1978; Shu and Richards, 2001; Rochefort et al., 2002). Neuroglia plays important roles in synapse formation during development, as well as in multiple forms of synaptic plasticity (Liu et al., 1994; Prewitt et al., 1997; Rochefort et al., 2002; López-Hidalgo and Schummers, 2014), whereas dynamic physical and molecular interactions between astrocytes and neurons control the morphology and structural plasticity of the dendritic spines. Once the appropriate synaptic connections are formed during the critical period of maturation and refinement, the function of astrocytes is likely modulated (Stevens, 2008). 
At molecular level, the evolutionary conservation of gene expression in the aging brain includes increase in stress and inflammatory responses, and loss of mitochondria, neural plasticity, autophagy, and synaptic functions (Loerch et al., 2008; Bishop et al., 2010).

The frontal cortex as brain region with high-order cognitive functions, includes the motor and the somatosensory area. It receives less-coordinated activation with aging, suggesting global alterations in the integrative functions (Andrews-Hanna et al., 2007). In neurodegenerative disorders such as Alzheimer's disease $(\mathrm{AD})$, cognitive and mnestic alterations are predictors of age-related cortical function. (Huttenlocher, 1990; Bishop et al., 2010). This cognitive decline in frontal cortex is rather associated with alterations in synaptic connectivity than with neuronal loss and white-matter changes (Mattson and Magnus, 2006; Balietti et al., 2012). Physiological and anatomical alterations associated with aging are accompanied by changes in vision-associated qualities, including visual acuity, perception of contrast and wavelength, and impairment of binocular capabilities (Weale, 1975; Kline et al., 1983; Ross et al., 1985; Schefrin et al., 1999; Nomura et al., 2003; Mavroudis et al., 2012).

Most morphological studies of postnatal development have focused on the visual cortex due to its clearly demarcated characteristic anatomy, such as its very large granular layer (Huttenlocher et al., 1982; Huttenlocher, 1990). Timing and magnitude of growth, branching, spinogenesis and pruning in the basal dendritic trees of pyramidal cells differ dramatically among sensory, association, and executive cortical areas (Elston et al., 2009, 2010a,b, 2011b; Elston and Fujita, 2014). In primary (V1) and secondary visual cortex (e.g., V2, V3, and V4) the number of spines decreases in contrast to its increase in cytoarchitectonic areas in the posterior portion of the inferior temporal cortex (TEO) from early postnatal stages till adulthood (Elston et al., 2010a). Moreover, prolonged growth periods of dendritic trees in the primary auditory cortex (A1), anterior ventral portion of the inferior temporal cortex (TEav) and granular prefrontal cortex (Brodmann's area 12) has been found compared to V1 (Cupp and Uemura, 1980; Anderson et al., 1995; Elston et al., 2009, 2011b). However, different growth profiles may reflect the type neuronal complexity and functional hierarchies in the adult brain (Jacobs and Scheibel, 2002; Elston, 2007; Spruston, 2008; Elston et al., 2009).

During aging a greater decline of complex pyramidal cells compared to simple cells has been found in the primary and secondary visual cortices of macaque monkeys (Liang et al., 2012). At morphological level, cerebral imaging has demonstrated the presence of atrophy of the visual cortex in aged humans (Park et al., 2004); those changes in vision-related areas of the brain include neurons (Satorre et al., 1985).

In addition to morphological alterations, the electrophysiological profile of pyramidal neurons also varies during postnatal development, maturation, and aging in different cortical layers, cortical areas, and species (Benavides-Piccione et al., 2002, 2006; Ballesteros-Yáñez et al., 2006; Elston et al., 2006b). Pyramidal cells in primary visual cortex (V1) show different electrophysiological profiles compared to granular prefrontal cortex and inferior temporal cortex (TE; Murayama et al., 1997; Amatrudo et al., 2012; Luebke et al., 2013). Those developmental differences in the electrophysiological signatures of pyramidal cells suggest different, specialized, and functional signatures of the adult cortex. Reflecting aging, measureable and significant losses of electrophysiological responses have been detected in the V1 of aged mammals (e.g., rats, cats, and New World monkeys) compared to their younger counterparts (Schmolesky et al., 2000; Hua et al., 2006; Wang et al., 2006). Moreover, different electrophysiological profiles have been found in primates in comparison to rodents during aging (McCormick and Prince, 1987; Kasper et al., 1994; Metherate and Aramakis, 1999; Zhang, 2004; Oswald and Reyes, 2008; Romand et al., 2011). The postnatal pyramidal cell development, spinogenesis, dendritic growth, and electrophysiological profiles varies considerably in different species and different cortical areas associated with visual processing (for review, see Elston and Fujita, 2014). However, perceptual deficits could not be explained by morphological alterations in the retina alone, and are probably only related to cortical areas (Satorre et al., 1985; Ahmad and Spear, 1993; Kim et al., 1996).

In a previous comparative proteomic analysis of the neuroretinas of marmosets and rats, we found that peroxiredoxin (Prx), beta-synuclein (SNCB), Parkinson's disease (PD; autosomal recessive, early onset) $7 / \mathrm{DJ}-1$ (DJ-1), and stathmin (STMN) were regulated in an age-related fashion in both species (Böhm et al., 2013). The aim of the present study was to explore the comparative expression characteristics of Prx, SNCB, DJ-1, and STMN in the primary somatosensory cortex (S1) and primary visual cortex (V1) of the rat. We presumed that significant regional differences were present in the expressions of the aforementioned proteins with respect to level of maturation and age between both the frontal and visual cortical areas. The rationale for using S1 and V1 was that these areas receive quite different afferent input, serve distinctly different functions, are topologically the most distant areas within the cortex, and show high divergence of pyramidal neuron morphometry together with the differential synaptic densities in the different cortical regions (e.g., prefrontal and somatosensory) cortex compared to the visual cortex (Geschwind and Rakic, 2013; Elston and Fujita, 2014). The distribution profiles and cellular localizations of the selected proteins are demonstrated herein, assigning them a generalized role in the processes in which they are involved in the brain.

\section{MATERIALS AND METHODS ANIMALS}

All animal work was conducted under the guidelines of the Animal Welfare Act and under the oversight and approval of the University and Governmental Institutional Animal Care and Use Committee (LANUV-NRW, Permission numbers 887-50.10.46.09.018 and 8-87-50.10.36.09.068 for rats). SpragueDawley rats were housed in standard animal rooms under a 12-/12-h light/dark cycle, with food and water provided ad libitum. In total, 72 rats (24 neonatal and 48 adult and/or elderly animals) were used, covering the following ages: postnatal 
day (P0) (i.e., the day of birth) ( $n=24$ animals), the youngadult stage (adolescence) -6 months after birth $(6 \mathrm{~m})(n=12$ animals), middle-age-12 and 18 months after birth (12 m and $18 \mathrm{~m}$, respectively) ( $n=12$ animals for each group), and aged (elderly)-30 months after birth $(30 \mathrm{~m})(n=12$ animals).

\section{BRAIN DISSECTION}

Protein and RNA extraction were achieved following microdissection of the selected cortical regions, according to Palkovits et al. (Palkovits and Brownstein, 1988; Chiu et al., 2007). In brief, the animals were euthanized and the brain was removed from the skull and rinsed in ice-cold diethylpyrocarbonate-treated Milli-Q water to remove any surface blood. The brain was then placed onto a cold metal plate and the right and left hemispheres were separated. The olfactory bulb was dissected out and discarded. Both areas of interest are well dissectible when the cortex is viewed from the dorsal aspect. To ensure that in both cases and in relation to different maturated brains the areas of interest are included, the parietal part of the most anterior pole was dissected to include S1 (respectively the primary somatosensory area), whereas the cranial part of the most occipital pole was dissected to include V1 (respectively the primary visual area). The barrel cortex was not considered in preparation of S1 in this study (Woolsey and Van der Loos, 1970; Woolsey et al., 1975). The selected region was flash frozen in liquid nitrogen and stored at $-80^{\circ} \mathrm{C}$ until use.

\section{WESTERN BLOTTING}

Probes (P0, $n=8,6-30 \mathrm{~m}, n=4$ for each group) obtained from either visual and frontal cortices were subsequently lysed in RIPA buffer [containing $0.1 \%$ sodium dodecylsulfate (SDS)] with additional protease inhibitor cocktail (Roche, Mannheim, Germany) and $1 \mathrm{mM}$ phenylmethylsulfonyl fluoride (Sigma-Aldrich), followed by further trituration and ultrasound treatment. The samples were sonicated and heated, and then the protein concentrations therein were determined using Bradford reagents (Bio-Rad, München, Germany). The samples were then transferred to SDS sample buffer containing $130 \mathrm{mM}$ Tris$\mathrm{HCl}$ (Carl Roth, Karslruhe, Germany), 10\% w/v SDS, 10\% mercaptophenol, 20\% glycerol, and $0.06 \% \mathrm{w} / \mathrm{v}$ bromophenol blue (all Sigma-Aldrich). Fifty micrograms of protein from each sample were fractionated on $12 \%$ and $14 \%$ SDSpolyacrylamide gels (depending on the molecular weight of the target protein) with a protein marker (Bio-Rad, Hercules, CA, USA). After electrophoresis, the proteins were transferred onto a nitrocellulose membrane (Whatman, GE Healthcare Europe, Freiburg, Germany). The blots were incubated in blocking solution containing 5\% fat-free dried milk (Carl Roth) and 0.1\% Tween-20 PBS (Sigma-Aldrich) for $1 \mathrm{~h}$, followed by incubation overnight at $4^{\circ} \mathrm{C}$ with a primary antibody, as listed in Table 1 . The control antibody, anticalnexin, was used at a dilution of 1:10,000. The membrane was then incubated with a horseradishperoxidase-conjugated secondary antibody (Sigma-Aldrich) in blocking solution for $1 \mathrm{~h}$ at room temperature. Antibodies were detected by enhanced chemiluminescence (Amersham, Rockville,
MD, USA), and the relative densities of the protein spots were analyzed using Alpha Ease (Alpha-Ease FC software 4.0, Alpha Innotech, Biozym Scientific, Vienna, Austria). The protein density of a fixed area was determined for each spot after subtracting the specific background density in the surrounding region. The spot density was correlated and corrected against the relative density of the particular application control. The spot density of the samples from the P0 group was defined as the respective reference values, and the relative values at the other ages were calculated. In cases of missing or sparsely expression levels in neonatal ages, those obtained at $6 \mathrm{~m}$ were defined as reference values. Means and standard deviations of the relative relationships of the proteins were obtained for gels of four individual samples, each run three times for each individual group. The data are presented as mean $\pm \mathrm{SD}$ values. The primary and secondary antibodies used are listed in Table 1.

\section{QUANTITATIVE REVERSE-TRANSCRIPTION POLYMERASE CHAIN REACTION}

RNA isolation from probes ( $\mathrm{P} 0, n=8,6-30 \mathrm{~m}, n=4$ for each group) was achieved using the RNeasy kit (Sigma-Aldrich) according to the protocols provided by the manufacturer. The results were quantified using a UV/visual spectral photometer (NanoDrop ND-1000, Peqlab, Erlangen, Germany). cDNA was synthesized from $1 \mu \mathrm{g}$ of total RNA using the High-Capacity cDNA Reverse Transcription Kit from Applied Biosystems (Darmstadt, Germany). The quantitative polymerase chain reaction (PCR) primer pairs were designed for SYBR-Greenbased real-time quantitative reverse-transcription polymerase chain reaction (qRT-PCR). The following primers were used in the PCR analysis:

\author{
Peroxiredoxin (Prx) 2: (NM_017169.1): \\ forward, CATGGCCTCCGGCAA; \\ reverse, AAAGGCACCATCCACCACGGC \\ Beta-Synuclein (SNCB): (NM_031686.1): \\ forward, GGGCCTTGTCCCATTCACGGC; \\ reverse, TGCCTGCTTCTATATCCCGGCTTGG \\ PARK [Parkinson disease (autosomal \\ recessive, early onset)]7/DJ-1 \\ (DJ-1): (NM_057143.1): \\ forward, ACCGCGCAGGAAAAACACGC; \\ reverse, CTGCCAGACGGCTCTGCAC \\ Stathmin (STMN) 1: (NM_017166.1): \\ forward, TCCGAGCCGCCTGGCTTAGG; \\ reverse, GTCCCGTGTCCCCGGCTAGG
}

qRT-PCR was performed using the SYBR Green PCR kit (Applied Biosystems) according to the protocols provided by the manufacturer. Relative protein expressions were calculated as $2-\Delta \mathrm{Ct}^{\text {specific gene }} / 2-\Delta \mathrm{Ct}^{\text {mean (housekeeping genes) }}$, using glyceraldehyde phosphate dehydrogenase as an endogenous housekeeping control gene. For relative quantification (RQ), the comparative $\mathrm{Ct}(\Delta-\Delta \mathrm{Ct})$ method was employed; the results are presented relative to the expression level at $\mathrm{P} 0$. The data are presented as mean $\pm \mathrm{SD}$ values. 
Table 1 | Primary and secondary antibodies used for Immunohistochemistry and Western-blot.

\begin{tabular}{llll}
\hline & & Immunohistochemistry & \\
\hline 1st Antibody & \multicolumn{1}{c}{ Species } & Solution & Company \\
\hline Peroxiredoxin (1-4) & Rabbit polyclonal & $1: 100$ & Santa-Cruz \\
DJ-1/Park7 & Rabbit polyclonal & $1: 100$ & Abcam \\
Beta-Synuclein & Rabbit polyclonal & $1: 200$ & Abcam \\
Stathmin 1 & Rabbit polyclonal & $1: 500$ & Abcam \\
NF-200 & Mouse monoclonal & $1: 200$ & Sigma \\
GFAP & Mouse monoclonal & $1: 250$ & Sigma \\
CD11b/c (OX-42) & Mouse monoclonal & $1: 50$ & Serotec \\
2nd Antibody & Species & Solution & Company \\
(Cy)-2 & Goat-Anti-mouse & $1: 400$ & Jackson Immunoresearch \\
TRITC & Goat-Anti-rabbit & $1: 400$ & Sigma \\
& & Western blot & \\
\hline & & & \\
1st Antibody & & Solution & kDa \\
Peroxiredoxin (1-4) & Species & $1: 4000$ & $25 \mathrm{kDa}$ \\
DJ-1/Park7 & Rabbit polyclonal & $1: 6000$ & $20 / 24 \mathrm{kDa}$ \\
Beta-Synuclein & Rabbit polyclonal & $1: 2000$ & $14 \mathrm{kDa}$ \\
Stathmin 1 & Rabbit monoclonal & $1: 1000$ & $17 \mathrm{kDa}$ \\
2nd Antibody & Rabbit polyclonal & Solution & kDa \\
Calnexin & Species & $1: 10000$ & $90 \mathrm{kDa}$ \\
\hline DJ-1, PARK (Parkingany & Santa-Cruz \\
& Rabbit polyclonal & Abcam \\
\end{tabular}

DJ-1, PARK [Parkinson disease (autosomal recessive, early onset)] 7/DJ-1; NF-200, high-molecular-weight neurofilament; GFAP, glial fibrillary acidic protein; CD11b/C, cluster of differentiation molecule 11b/c; (Cy)-2, cyanine; TRITC, tetramethylrhodamine; kDa, kilodalton.

\section{IMMUNOHISTOCHEMISTRY}

The regional localization and cellular expression of Prx (1-4), SNCB, DJ-1, and STMN in cortical cells was explored using immunohistochemistry (IHC). The animals (P0, $n=8,6-30 \mathrm{~m}$, $n=4$ for each group) were given a lethal overdose of anesthesia induced using a mixture of $10 \%$ ketamine (Ceva Sanofi, Düsseldorf, Germany) and xylazine (Cefa Sanofi), and then perfused transcardially with phosphate-buffered saline (PBS; Sigma-Aldrich, Taufenkirchen, Germany) followed by $500 \mathrm{ml}$ of a fixative containing 4\% paraformaldehyde (PFA, $\mathrm{pH} 7.4$ ) in $10 \mathrm{mM}$ PBS. The brain of each animal was then extracted and postfixed in 4\% PFA for $24 \mathrm{~h}$. Fixed samples were processed in an automated tissue processor (Bavimed Histomaster 2062-DI 2L, Birkenau, Germany) and then transferred directly into $70 \%$ ethanol for $8 \mathrm{~h}$ prior to initiation of processing, followed by incubation for $15 \mathrm{~min}$ in each of the following: $99 \%$ ethanol, $96 \%$ ethanol, xylene $(\times 2)$, and paraffin $(\times 2)$. They were then infiltrated with lowmelting-point paraffin wax (Sasol Wax, Hamburg, Germany) for $1 \mathrm{~h}$ at $56^{\circ} \mathrm{C}$ three times, with each brain being embedded separately. The paraffin-embedded brains were kept dry at $4^{\circ} \mathrm{C}$ until use.

The paraffin-embedded brains were sectioned coronally at a thickness of $4 \mu \mathrm{m}$ using a microtome (CM 1500, Leica, Bremen, Germany), and mounted onto glass slides. The procedure for selecting slices of the region of interest is described briefly further below in the method section.

Before immunohistochemical staining, the selected slides/ sections were warmed (at $60^{\circ} \mathrm{C}$ for $30 \mathrm{~min}$ ) and then deparaffinized by soaking them twice in xylene for $10 \mathrm{~min}$ each time (Panreac Appli-Chem, Darmstadt, Germany), followed by two 3-min drenches in $99 \%, 96 \%$, and $70 \%$ ethanol, followed by distilled water. After rinsing the slides with PBS $(2 \times 5 \mathrm{~min})$, the sections were incubated for $30 \mathrm{~min}$ with blocking solution containing $10 \%$ goat serum (Sigma-Aldrich) for $2 \mathrm{~h}$ at room temperature, and then with primary antibodies overnight at $4^{\circ} \mathrm{C}$. After washing, the sections were incubated with secondary antibodies ( $1 \mathrm{~h}$ at room temperature), washed in PBS, and then coverslipped with antifade mounting medium (Mowiol, Hoechst, Frankfurt, Germany) containing 4,6-diamidino-2-phenylindole to stain the cell nuclei. Primary and secondary antibodies are provided in Table 1.

\section{VERIFICATION AND IDENTIFICATION OF Prx, SNCB, DJ-1, AND STMN IN VARIOUS CORTICAL CELL TYPES}

Differences in the expressions of Prx, SNCB, DJ-1, and STMN in different cortical cell types were analyzed by immunohistochemical staining of both the frontal and visual cortices. First, selected slices were routinely stained with hematoxylin and eosin (H\&E) for basic morphological evaluation including comparison with the rat brain maps illustrated by Swanson (1992). The primary somatosensory cortex (S1) and primary visual cortex (V1) were correctly localized on examination of selected H\&E-stained slides with bright-light microscopy (data not shown). Slices of selected regions were then immunohistochemically stained as described above.

Each section was stained with both an antibody detecting one of the cortical cell types-high-molecular-weight neurofilament (NF-200) for neuronal cells, glial fibrillary acidic protein (GFAP) for glial cells, or cluster of differentiation molecule 11b/c (OX-42) for brain microglia- and an antibody detecting Prx, SNCB, DJ-1, 
or STMN (Nadeau and Rivest, 2000). Colocalization of a celltype-specific antibody with a specific protein antibody indicates expression of that particular protein in that particular cell type. Negative controls comprised sections that were processed as for the other sections but without the addition of a primary antibody. Control and experimental sections were stained simultaneously to avoid variations in immunohistochemical staining. Primary and secondary antibodies are provided in Table 1.

The slides were viewed with the appropriate filter on a microscope equipped with epifluorescence (Apotome 2, Carl Zeiss, Jena, Germany) and appropriate software (ZEN 2012, Carl Zeiss). Z-stacks were applied and evaluated to identify the cellular localization of the proteins. The regions of interest were then analyzed qualitatively as follows. Digital images of three microscopic fields (non-overlapping) in each hemisphere of at least three independent samples were taken at a magnification of $\times 20$ to enable quantification of the level of each of the selected cortical cells within layer IV (for pyramidal neurons), layer I (for glial cells, e.g., astrocytes), and layer I-V (for microglia) were distinguished from other layers by the presence of larger pyramidal neurons. The barrel cortex was not considered in studying S1 (Woolsey and Van der Loos, 1970; Woolsey et al., 1975). A counting box of dimensions $300 \mu \mathrm{m} \times 300 \mu \mathrm{m}$ (a buffer zone of $10 \mu \mathrm{m}$ on either surface was employed so as not to include cut surfaces and to spare out the edges) was superimposed onto the image to aid counting. The number of cortical cells obtained from DAPI merged images within the region of interest was counted with the cell count function of ImageJ software. ${ }^{1}$ Each of the automated counts was double checked manually, and cells were assessed only if the cell body was easily seen and had no secondary branches obscured by background staining or by another cell. Any specific cortical cell body that was immunopositive for the protein under analysis, independent of its intensity, was then counted manually.

The focus of these analyses was to reveal the relative number of double-labeled cells. These data were used to calculate the rates of costaining $[\%=$ (number of cell body positive for selected protein/number of cortical cell type $\times 100)$ ] in the cortex of each age, as well as the means of the individual experimental groups. The data are presented as mean \pm SD values. The method of counting and calculating the rates of costaining was performed according to $\mathrm{He}$ et al. (2014). Although ideally we would like to have estimated the total number of neurons, it was not possible to demarcate these frontal and visual-associated brain areas in order to estimate their entire volume, and so we relative neuron cell count was used to represent neuronal densities, as described previously.

\section{DATA EVALUATION AND STATISTICS}

All data regarding the means of specific costaining studies from IHC, optical density from Western blot (WB) analyses, and relative quantification from qRT-PCR studies were analyzed with a test for two independent samples (IBM SPSS Statistics

\footnotetext{
${ }^{1}$ http://imagej.nih.gov/ij/
}

20.0) to examine conformity with the Gaussian distribution, and processed using the ANOVA (for a Gaussian distribution) and Friedman test (for a non-Gaussian distribution). Local $p$ values were corrected for multiple comparisons using the HolmBonferroni method. $p$-Value $<0.05$ were judged as statistical significant. Figures were prepared with image-processing software (Photoshop, Adobe Systems, San Jose, CA, USA), and the overall brightness and contrast were adjusted without retouching.

\section{RESULTS}

First, the expressions of Prx, SNCB, DJ-1, and STMN in the S1 and V1 were verified at the protein and gene level using WB and qRT-PCR. Then, the cellular localization of the four proteins was examined immunohistochemically by double-staining S1 and V1 sections with antibody markers for three different cortical subsets of cells (neurons, glial elements, and microglial cells) and antibodies to Prx, SNCB, DJ-1, and STMN.

\section{PEROXIREDOXIN}

\section{Protein expression levels}

WB analysis of Prx expression at $6 \mathrm{~m}(\mathrm{~S} 1,128.5 \pm 8.1 \%, p=0.07$; $\mathrm{V} 1,94.6 \pm 15.5 \%, p=0.6), 12 \mathrm{~m}(\mathrm{~S} 1,123.5 \pm 13.8 \%, p=0.3 ; \mathrm{V} 1$, $156.0 \pm 47.8 \%, p=0.3), 18 \mathrm{~m}(\mathrm{~S} 1,123.1 \pm 1.8 \%, p<0.05 ; \mathrm{V} 1$, $111.6 \pm 23.6 \%, p=0.5)$, and $30 \mathrm{~m}(\mathrm{~S} 1,116.1 \pm 19.7 \%, p=0.3$; V1, $80.3 \pm 25.2 \%, p=0.5)$ revealed comparable expressions of $\operatorname{Prx}(25 \mathrm{kDa})$ in both cortical areas at all ages compared to P0 (Figures 1A,B). These data indicate that although there was a tendency toward changes in protein expression with age, the differences were not statistically significant.

\section{mRNA expression levels}

Prx mRNA level was significantly decreased at $6 \mathrm{~m}(\mathrm{~S} 1, \mathrm{RQ}=0.42$ $\pm 0.004, p<0.05 ; \mathrm{V} 1, \mathrm{RQ}=0.43 \pm 0.07, p<0.05), 12 \mathrm{~m}(\mathrm{~S} 1$, $\mathrm{RQ}=0.53 \pm 0.03, p<0.05 ; \mathrm{V} 1, \mathrm{RQ}=0.47 \pm 0.06, p<0.05), 18 \mathrm{~m}$ $(\mathrm{S} 1, \mathrm{RQ}=0.54 \pm 0.01, p<0.05 ; \mathrm{V} 1, \mathrm{RQ}=0.41 \pm 0.05, p<0.05)$, and $30 \mathrm{~m}(\mathrm{~S} 1, \mathrm{RQ}=0.45 \pm 0.03, p<0.05 ; \mathrm{V} 1, \mathrm{RQ}=0.46 \pm$ $0.12, p<0.05$ ) compared to P0 (Figure 1C). These data show that Prx mRNA levels are decreased at all ages compared to P0, and confirmed the data observed at the IHC level.

\section{Immunohistochemistry}

The colabeling study revealed that Prx is expressed in neurons, glial cells, and microglia. Prx was localized mainly in the cytoplasm and in close association with the nucleus in NF-200positive neuronal cells, GFAP-positive glial cells, and OX-42positive microglial cells in the newborn cortex (Figures 1D-G). In the aged cortex, Prx was localized only in close association with the nucleus of neuronal cells and microglial cells (Figures 1H-K).

\section{Neuronal staining}

Prx was detected in neurons at all ages examined, and its distribution changed slightly with aging in both the S1 and V1. At the cellular level, at P0 Prx was costained with NF-200-positive neurons in both cortical areas (S1, 90.7 \pm 8.1\%; V1, 82.6 $\pm 10.6 \%$; $p=0,2$; Figure 1L). A decrease of these Prx-positive neuronal cells compared to P0 was found for both the S1 and V1 in the 
A

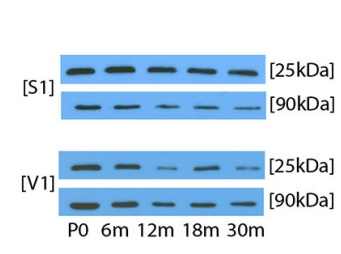

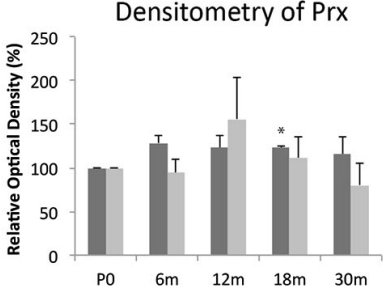

C

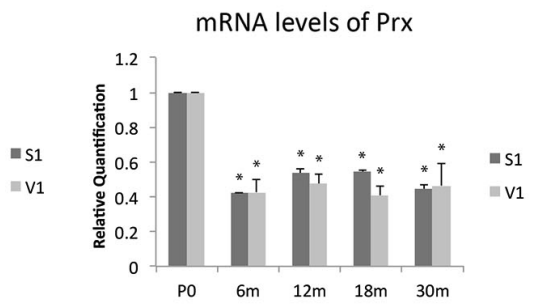

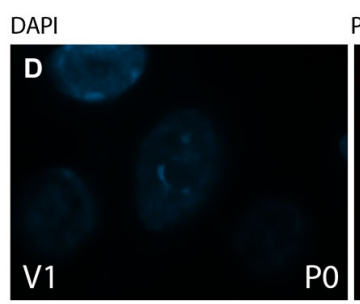

Prx

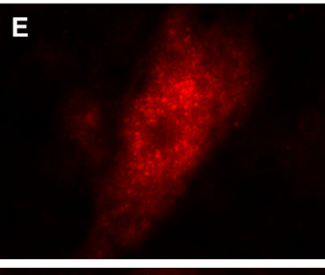

NF-200
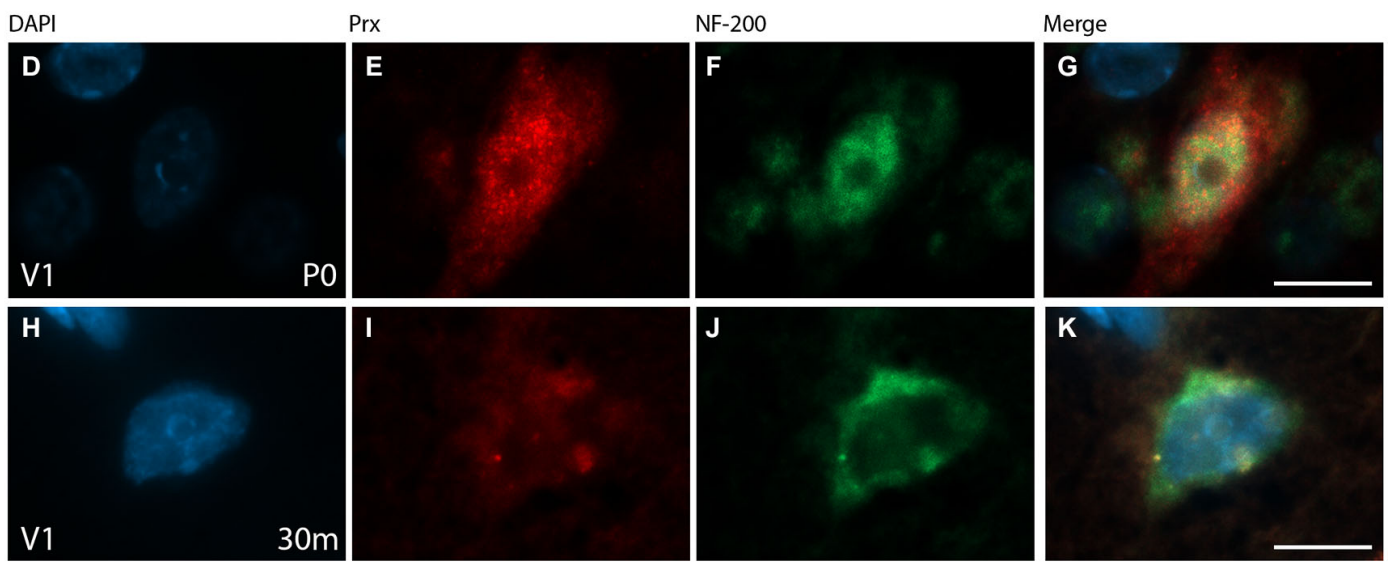

Prxt / NF-200+ cortical cells
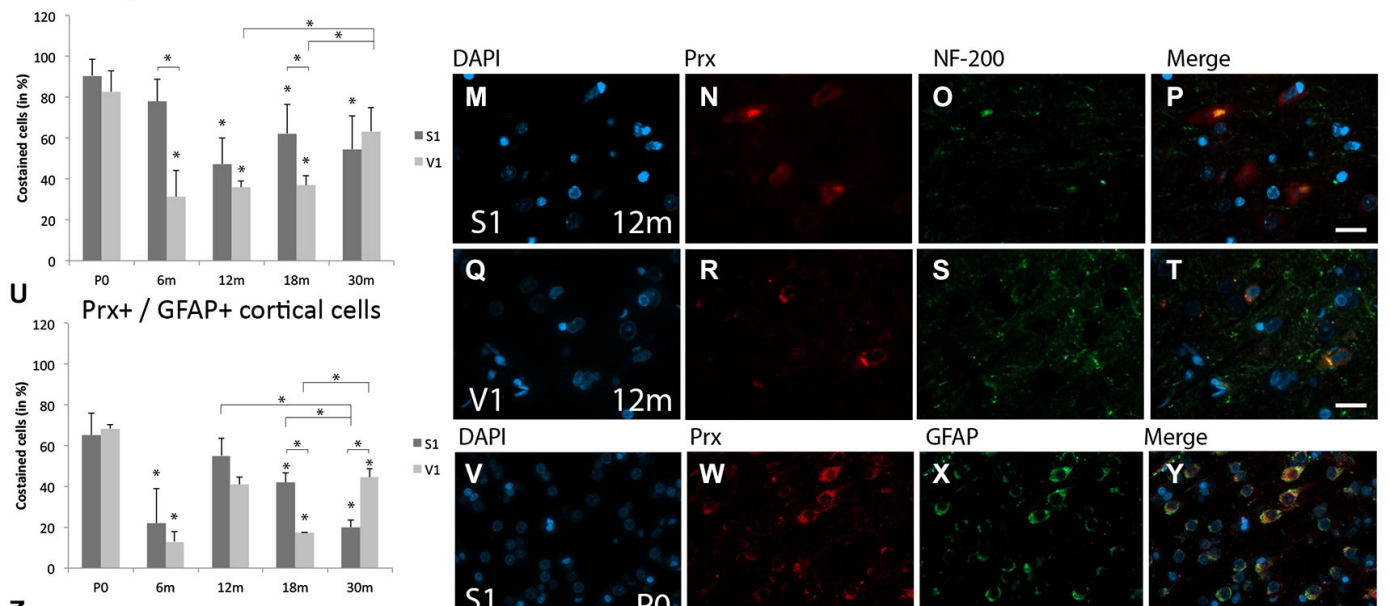

Z

Prx+ / OX-42+ cortical cells
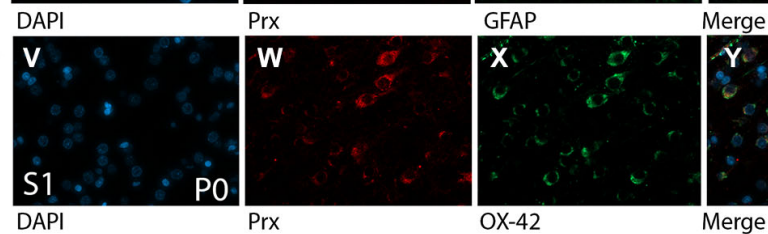

Merge
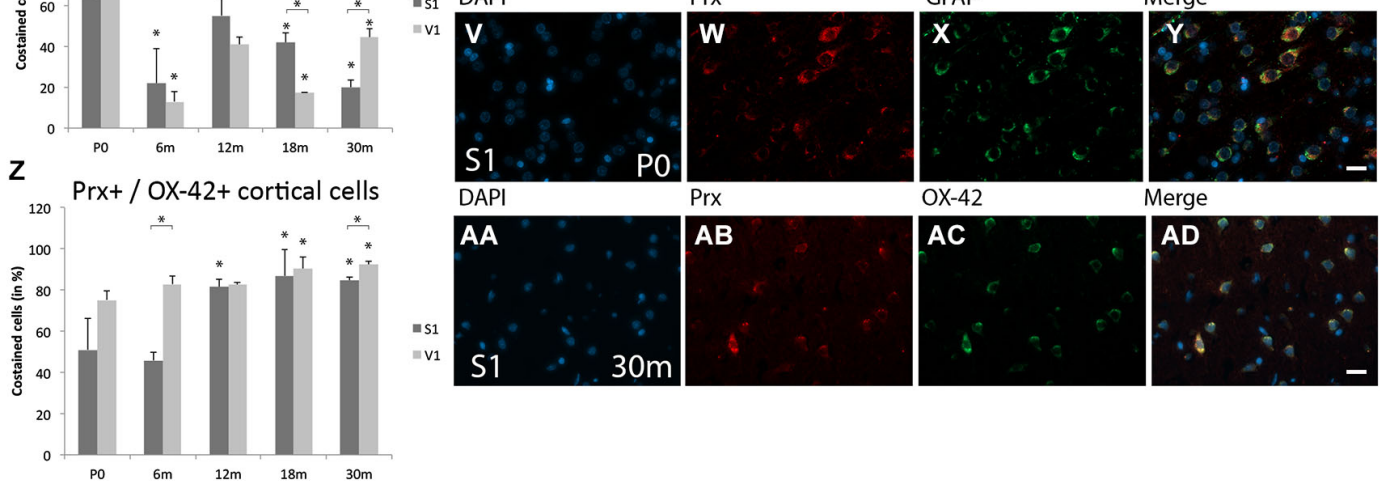

FIGURE 1 | Age-related expression and regulation of peroxiredoxins 1-4 (Prx) in the rat primary somatosensory cortex (S1) and primary visual cortex (V1). (A) Western-blot analyses of cortex and (B) corresponding densitometric analyses of the Western-blot results relative to those measured at PO (in \%). Lysates of cortex treated as described in the main text were prepared and tested for $\operatorname{Prx}(25 \mathrm{kDa})$ expression. Calnexin expression verified the amount of protein loaded per lane. Protein bands are given in kilodaltons (kDa). (C) Quantitative reverse-transcription polymerase chain reaction (qRT-PCR) results for $\mathrm{Pr}$
mRNA levels relative to those measured at P0. Expression of cortical Prx (red) and several cortical cell types (green) revealed by immunohistochemical staining of $4-\mu \mathrm{m}$-thick sections of brain samples. (D-K) The intra- and extracellular localizations of Prx in neonatal (P0) and 30 months aged $(30 \mathrm{~m})$ V1 were detected in high-molecular-weight neurofilament (NF-200)-positive neuronal cells at higher magnification ( $\times 63)$. The rate of costained cells $[\%=(\#$ of $\operatorname{Pr} x+/$ cortical cell type + )/(\# of cortical cell type+) $\times$ 100] (He et al., 2014) is shown with

(Continued) 


\section{FIGURE 1 | Continued}

(L-T) NF-200 for neuronal cells in S1 and V1 at $12 \mathrm{~m}$, (U-Y) glial fibrillary acidic protein (GFAP) for glial cells in $\mathrm{S} 1$ at $\mathrm{PO}$, and (Z,AA-AD) cluster of differentiation molecule $11 \mathrm{~b} / \mathrm{c}(\mathrm{OX}-42)$ for microglial cells in $\mathrm{S} 1$ at $30 \mathrm{~m}$. The negative control was performed with cyanine (Cy)-2 and

tetramethylrhodamine (TRITC) as secondary antibodies (data not shown). 4',6'-Diamidino-2-phenylindole (DAPI) was used to stain the cell nuclei.

Scale bars: (D-K), $10 \mu \mathrm{m}$; (M-P), (Q-T), (V-Y), and (AA-AD), $20 \mu \mathrm{m}$.

* Statistically significant difference at $p<0.05$; * standing by itself mean statistically significant differences in relation to PO.

adult stages (e.g., $12 \mathrm{~m}: \mathrm{S} 1,47.4 \pm 12.9 \%, p<0.05$; V1, $35.9 \pm$ $2.9 \%, p<0.05 ; 18 \mathrm{~m}: \mathrm{S} 1,62.4 \pm 14.2 \%, p<0.05 ; \mathrm{V} 1,38.9 \pm$ $4.6 \%, p<0.05$ ) compared to P0 (Figures $1 \mathrm{~L}-\mathrm{T}$ ). The proportion of Prx-positive neurons continued to decline between the adult (e.g., $18 \mathrm{~m}$ ) and elderly stages (30 m, 54.6 $\pm 16.3 \%, p=0.57$ ), and remained decreased compared to P0 $(p<0.05)$ in the S1. The proportion of Prx-positive neuronal cells was comparable between $\mathrm{S} 1$ and $\mathrm{V} 1$ in adult stages of age $(12 \mathrm{~m}, p=0.4 ; 18 \mathrm{~m}$, $p=0.1)$. There was a tendency toward an increase in Prx-positive neurons at $\mathrm{P} 30 \mathrm{~m}$ in the $\mathrm{V} 1(63.4 \pm 11.8 \%, p<0.05)$ compared to adult stages (e.g., $18 \mathrm{~m}$ ). No differences within the V1 between the ages $30 \mathrm{~m}$ and P0 were observed $(p=0.1$ ) (Figure 1L).

\section{Glial staining}

At P0, comparable colabeling of Prx with GFAP-positive gial cells was found in both the $\mathrm{S} 1(65.3 \pm 10.7 \%)$ and V1 $(68.4 \pm 2 \%$, $p=0.8$ ) (Figures 1U-Y). In the adult stages there was a decrease in glial Prx expression in both the S1 $(18 \mathrm{~m}, 41.9 \% \pm 4.9 \%, p<0.05)$ and V1 $(18 \mathrm{~m}, 17.5 \% \pm 0.1 \%, p<0.05)$ compared to P0. At $30 \mathrm{~m}(20.1 \pm 3.4 \%)$, the proportion of Prx-positive glial cells had decreased further in the S1 compared to both the neonatal $(20.1$ $\pm 3.4 \%, p<0.05)$ and the adult stages $(12 \mathrm{~m}, 55.2 \% \pm 8.4 \%$, $p<0.05 ; 18 \mathrm{~m}, p<0.05)$. In contrast, there was an increase in the proportion of Prx-positive glial cells in the V1 at $30 \mathrm{~m}(44.6 \pm$ $4.0 \%$, ) compared to adult rats $(12 \mathrm{~m}, 41.0 \% \pm 3.7 \%, p=0.3 ; 18 \mathrm{~m}$, $p<0.05)$. There was a statistically significant difference between the $\mathrm{S} 1$ and $\mathrm{V} 1$ at $18 \mathrm{~m}(p<0.05)$ and $30 \mathrm{~m}(p<0.05)$ (Figure 1U).

\section{Microglial staining}

There was an increase in the proportion of OX-42-positive microglial cells colabeld with Prx in both cortical regions, with only slight differences between $\mathrm{S} 1$ and $\mathrm{V} 1$, beginning at P0 (S1, 51.0 $\pm 15.3 \% ; \mathrm{V} 1,75.2 \pm 4.5 \%, p=0.1)$ (Figure 1Z). Prx-positive staining of microglia increased with age, with intense staining being detected at $30 \mathrm{~m}$ in both cortical areas $(\mathrm{S} 1,84.7 \% \pm 1.7 \%, p<0.05 ; \mathrm{V} 1,92.3 \pm 1.4 \%$, $p<0.05)$ compared to $\mathrm{P} 0$. There was a strong correlation of Prx staining in microglial cells and age in both cortical areas. An increased proportion of colabeled cells was present in the $\mathrm{S} 1$ at $12 \mathrm{~m}, 18 \mathrm{~m}$ and $30 \mathrm{~m}$. A high colabeling rate of Prx and microglia was observed in the $\mathrm{V} 1$ in all stages of age (Figures 1AA-AD).

\section{BETA-SYNUCLEIN}

\section{Protein expression levels}

Since SNCB was only sparsely detected in the S1 at P0, the expression at $6 \mathrm{~m}$ was used as a reference for optical density at later stages. The expression of SNCB was lower at P0 (S1, 1.33 $\pm 0.07 \%, p<0.05 ; \mathrm{V} 1,38.3 \pm 13.3 \%, p<0.05)$ than at $6 \mathrm{~m}$. An increase in SNCB expression was detected in both the S1 $(146.5 \pm 4.4 \%, p<0.05)$ and V1 $(104.4 \pm 19.4 \%, p<0.05)$ at $12 \mathrm{~m}$. There was no significant increase in SNCB expression in the $\mathrm{S} 1$ at $18 \mathrm{~m}(189.0 \pm 61.0 \%, p=0.06)$, while there was a significant increase in the V1 $(115.5 \pm 14.5, p<0.05)$. Although no significant alterations in SNCB expression were detected in the aged S1 $(209.5 \pm 133.3 \%, p=0.08)$, there was a significant increase in the aged V1 $(175.3 \pm 14.4 \%, p<0.05$; Figures 2A,B).

\section{mRNA expression levels}

SNCB mRNA levels were slightly up-regulated at $6 \mathrm{~m}$ in the S1 $(\mathrm{RQ}=1.1 \pm 0.04, p<0.05)$, but remained unchanged in the V1 $(\mathrm{RQ}=0.96 \pm 0.4, p=0.4)$. The greatest degree of SNCB mRNA up-regulation was found at $12 \mathrm{~m}$ in the $\mathrm{V} 1$ (RQ $=1.2 \pm 0.09$, $p<0.05)$; the slight up-regulation of SNCB mRNA detected in the $\mathrm{S} 1$ was not statistically significant $(\mathrm{RQ}=1.4 \pm 0.24, p=0.07)$. The expression of this protein's mRNA remained unchanged at $18 \mathrm{~m}(\mathrm{~S} 1, \mathrm{RQ}=1.15 \pm 0.16, p=0.2 ; \mathrm{V} 1, \mathrm{RQ}=1.2 \pm 0.2, p=0.5)$ and $30 \mathrm{~m}(\mathrm{~S} 1, \mathrm{RQ}=1.1 \pm 0.25, p=0.4 ; \mathrm{V} 1, \mathrm{RQ}=1.1 \pm 0.23$, $p=0.2$ ) compared to $\mathrm{P} 0$ (Figure $2 \mathrm{C}$ ).

These data show that the expression of SNCB increased significantly at both the protein and mRNA levels during maturation of the brain, and then remained stable after $6 \mathrm{~m}$ in the V1, and increased slightly after $18 \mathrm{~m}$ in the S1.

\section{Immunohistochemistry}

A faint staining for SNCB was observed in both the S1 and V1 in the neonate, with an overall increase with age. SNCB was localized to the cytoplasm of neuronal cells at younger ages, while in aged cortical glial cells SNCB was found in close association with the nucleus (Figures 2D-K).

\section{Neuronal staining}

Comparable SNCB-positive neuronal cells were found in neonatal rat cortices (S1, 95.9 \pm 7.2\%; V1, $93.9 \pm 10.6 \% ; p=0.8$; Figures 2L-P). Its proportion of costained cells decreased with age and remained stable until the adult ages in both the $\mathrm{S} 1$ (e.g., $6 \mathrm{~m}: 52.6 \pm 20.4 \%, p<0.05$ ) and V1 (e.g., $6 \mathrm{~m} 35 \pm 7.5 \%$; $p<0.05)$. An increase of SNCB colabeled neuronal cells was detected in the V1 beginning at $18 \mathrm{~m}(87.5 \pm 4.6 \%, p<0.05$; $30 \mathrm{~m}, 58.9 \pm 1.9 \%, p<0.05)$ compared to $12 \mathrm{~m}(40.3 \pm 5.9 \%)$. The analyses revealed no change in neuronal SNCB staining in the $\mathrm{S} 1$ at this same stage $(12 \mathrm{~m}, 47.3 \% \pm 9 \%, p=0.7 ; 18 \mathrm{~m}, 41 \pm$ $12.5 \%, p=0.4$ ) compared to $6 \mathrm{~m}$. This pattern changed after $18 \mathrm{~m}$, with an increase in the proportion of SNCB-positive neurons with age up to $30 \mathrm{~m}(67.3 \pm 20.8 \%)$, resulting in a distinct, but not significant increase of NF-200- and SNCB-positive cells in the S1 compared to adult stages of age (e.g., $18 \mathrm{~m}, p=0.11$; Figure $2 \mathrm{~L}$ ).

\section{Glial staining}

There was a direct correlation between SNCB and GFAP-positive cells at P0 in both the $\mathrm{S} 1(65.2 \pm 14.9 \%)$ and V1 $(70.9 \pm 13.7 \%$; $p=0.6$; Figures $2 \mathbf{Q}-\mathbf{U})$. However, this close relationship between SNCB and glial cells decreased at $6 \mathrm{~m}(\mathrm{~S} 1,20.4 \pm 11.1 \%, p<0.05$; 


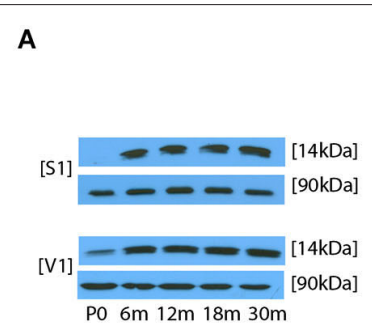

B

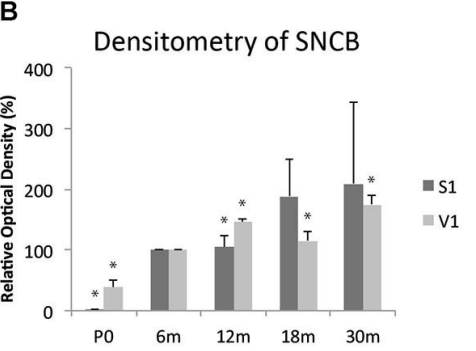

C

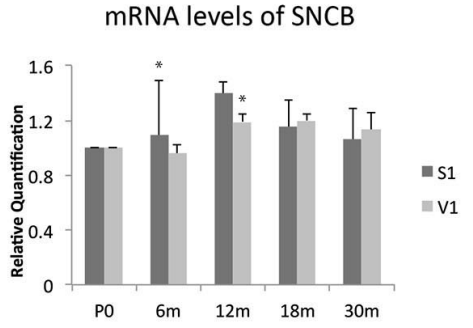

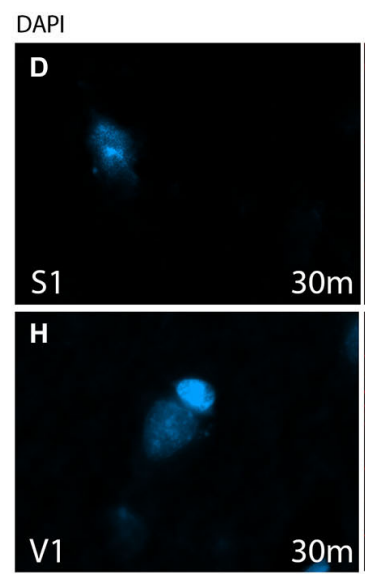

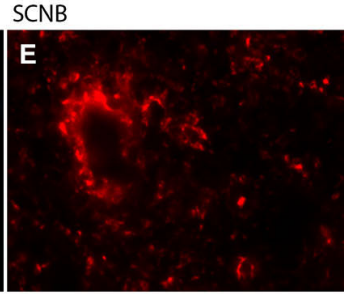

GFAP

Merge
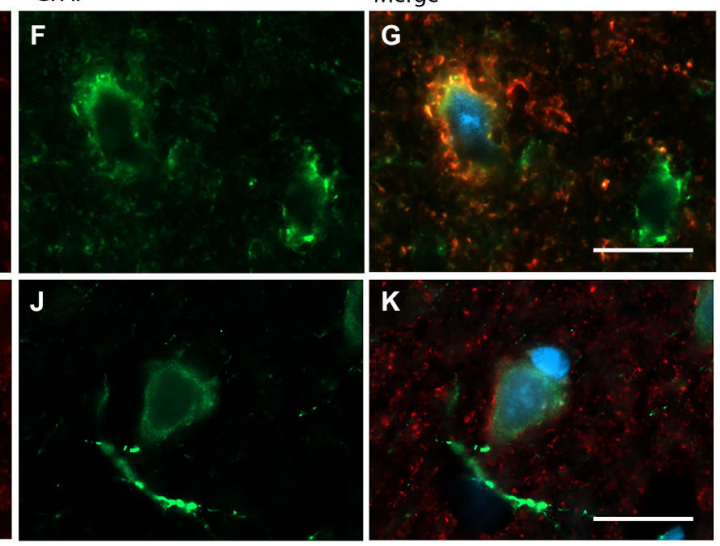

L

$\mathrm{SNCB}+/ \mathrm{NF}-200+$ cortical cells

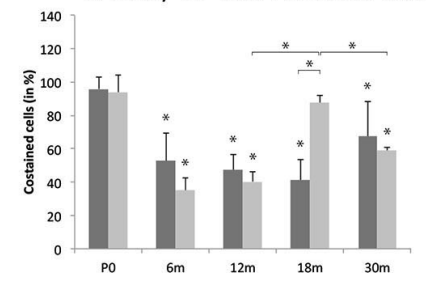

Q $\quad \mathrm{SNCB}+/ \mathrm{GFAP}+$ cortical cells

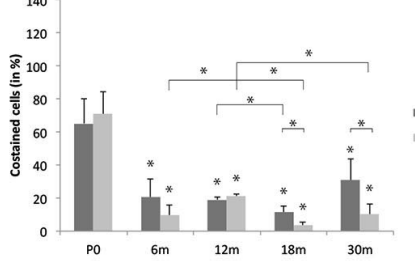

V SCNB $+/$ OX-42+ cortical cells

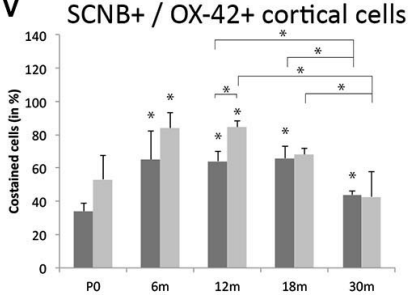

$m \mathrm{~s} 1$
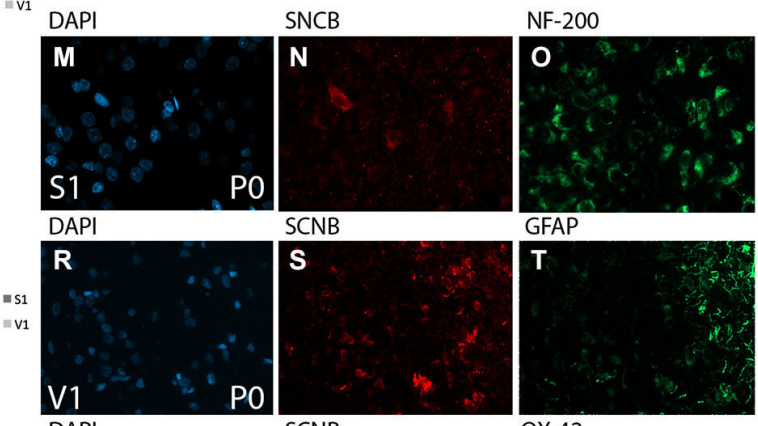

GFAP
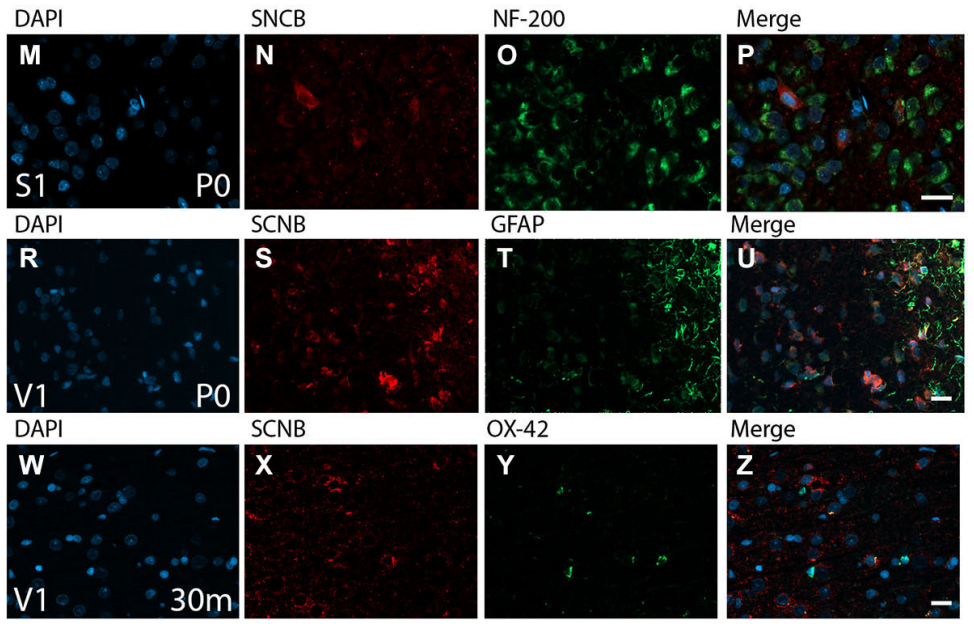

SCNB

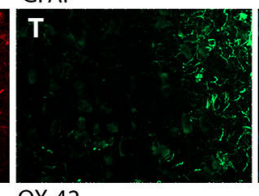

Merge

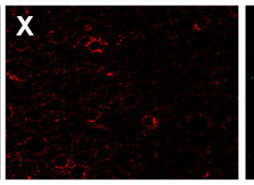

OX-42
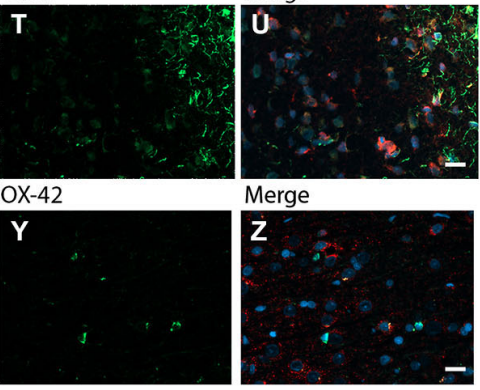

Merge

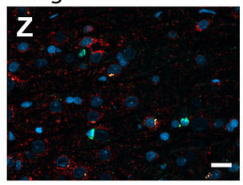

FIGURE 2 | Age-related expression and regulation of beta-synuclein (SNCB) in the rat S1 and V1. (A) Western-blot analyses of cortex and (B) corresponding densitometric analyses of the Western-blot results relative to those measured at 6 months $(6 \mathrm{~m}$ ) of age (in \%). Lysates of retinas treated as described in the main text were prepared and tested for SNCB (14 kDa) expression. Calnexin expression verified the amount of protein loaded per lane. Protein bands are given in kilodaltons. (C) Quantitative reverse-transcription polymerase chain reaction (qRT-PCR) results for SNCB mRNA levels relative to those measured at PO. Expression of cortical SNCB (red) and several cortical cell types (green) revealed by immunohistochemical staining of $4-\mu \mathrm{m}$-thick sections of brain samples. (D-K) Intra- and extracellular localizations of SNCB in aged $(30 \mathrm{~m}) \mathrm{S} 1$ and $\mathrm{V} 1$ were detected in GFAP-positive glial cells at higher magnification (63x). Rate of costained cells is shown in different cortical cell types: (L-P) Association between SNCB and

(Continued) 


\section{FIGURE 2 | Continued}

NF-200-positive neuronal cells is demonstrated in S1 at P0. (Q-U)

Colabeling of SNCB and GFAP-positive glial cells is shown in S1 at neonatal

level. (V-Z) Costaining of SNCB and OX-42 was performed in V1 at $30 \mathrm{~m}$.

The negative control was performed with $\mathrm{Cy}-2$ and TRITC as secondary

antibodies (data not shown). DAPI was used to stain the cell nuclei. Scale

bars: (D-K), $10 \mu \mathrm{m}$; (M-P), (R-U), and (W-Z), $20 \mu \mathrm{m}$. ${ }^{*}$ Statistically

significant difference at $p<0.05$. * standing by itself mean statistically

significant differences in relation to (B) $6 \mathrm{~m}$ and $(\mathbf{C}, \mathbf{L}, \mathbf{Q}, \mathbf{V}) \mathrm{PO}$.

V1, $9.7 \pm 5.8 \%, p<0.05)$ till elderly stages of age. A further decline in colabeling of SNCB in glial cells were found in both the $\mathrm{S} 1$ and $\mathrm{V} 1$ at $18 \mathrm{~m}(\mathrm{~S} 1,19 \pm 1.7 \%, p<0.05 ; \mathrm{V} 1,3.4 \pm 2.2 \%$, $p<0.05)$ and in V1 at $30 \mathrm{~m}(10.2 \pm 6.0 \%, p<0.05)$ compared to $12 \mathrm{~m}(\mathrm{~S} 1,19 \% \pm 1.7 \% ; \mathrm{V} 1,21.3 \pm 2.3 \%)$ (Figure 2Q).

\section{Microglial staining}

In agreement with the finding of slight immunostaining for SNCB in microglial cells in both cortices at P0 (S1, $34.1 \pm 4.5 \%$; V1, $53.2 \pm 14.3 \% ; p=0.08)$, there was an increase in the proportion of microglial cells positive for SNCB in both the S1 and V1 in the adult ages (e.g., $6 \mathrm{~m}$ : S1, 64.9\%17.3\%, $p<0.05 ; \mathrm{V} 1,83.9 \pm$ $9.4 \%, p<0.05$ ) (Figure 2V). This proportion then decreased in both cortices in elderly rats $(30 \mathrm{~m}: \mathrm{S} 1,43.9 \pm 2.2 \%$; V1, $42.7 \pm$ $14.8 \%$ ) compared to adult age stages (e.g., $12 \mathrm{~m}$ : S1, 64.1 $\pm 6.2 \%$; $p<0.05$; V1, $84.4 \pm 4 \%$; $p<0.05$ ) (Figures 2V-Z).

\section{DJ-1}

\section{Protein expression levels}

$\mathrm{WB}$ analysis revealed expression of DJ-1 in the $\mathrm{V} 1$ at all age stages. However, expression of DJ-1 was only sparsely detected in the neonatal S1. Compared to $6 \mathrm{~m}$, there was a reduced expression of DJ-1 in both the S1 $(1.4 \pm 0.5 \%, p<0.05)$ and V1 $(34.8 \pm 29.5 \%$, $p<0.05)$. With increased age, significantly more DJ-1 was found in both cortices at $12 \mathrm{~m}(\mathrm{~S} 1,140.8 \pm 27.3 \%, p<0.05 ; \mathrm{V} 1,137.4$ $\pm 15.7 \%, p<0.05)$. However, at $18 \mathrm{~m}$ increased DJ-1 expression was detected in the V1 $(143.8 \pm 39.1 \%, p<0.05)$, but not in the S1 $(155.5 \pm 88.2 \%, p=0.07)$. Increased expression of DJ-1 was detected in the aged (30 m) S1 (148.1 $\pm 58.6 \%, p<0.05)$, but not in the V1 at the same age $(76.1 \pm 45.9 \%, p=0.2$; Figures 3A,B).

\section{mRNA expression levels}

DJ-1 mRNA levels were significantly decreased in both the $\mathrm{S} 1$ and $\mathrm{V} 1$ at $6 \mathrm{~m}(\mathrm{~S} 1, \mathrm{RQ}=0.42 \pm 0.01, p<0.05 ; \mathrm{V} 1, \mathrm{RQ}=0.44 \pm 0.02$, $p<0.05), 12 \mathrm{~m}(\mathrm{~S} 1, \mathrm{RQ}=0.69 \pm 0.02, p<0.05 ; \mathrm{V} 1, \mathrm{RQ}=0.64 \pm$ $0.1, p<0.05), 18 \mathrm{~m}(\mathrm{~S} 1, \mathrm{RQ}=0.45 \pm 0.2, p<0.05 ; \mathrm{V} 1, \mathrm{RQ}=0.49$ $\pm 0.004, p<0.05)$, and $30 \mathrm{~m}(\mathrm{~S} 1, \mathrm{RQ}=0.52 \pm 0.5, p<0.05 ; \mathrm{V} 1$, $\mathrm{RQ}=0.66 \pm 0.09, p<0.05$ ) compared to P0 (Figure 3C). These data reveal a slight up-regulation of DJ-1 protein, but an overall reduction in its $\mathrm{mRNA}$.

\section{Immunohistochemistry}

IHC for DJ-1 revealed stained cells in the S1 and V1 at all ages (Figures 3D-K). DJ-1 was localized to the cytoplasm of all cell types examined, including NF-200-positive neuronal cells, GFAPpositive glial cells, and OX-42-positive microglial cells in both the $\mathrm{S} 1$ and V1.

\section{Neuronal staining}

Colabeling of DJ-1 and NF-200-positive neurons was found at all ages (Figure 3L). Different costaining of DJ-1 and NF-200 was found in newborn rats in $\mathrm{S} 1(91.1 \pm 3.6 \%)$ compared to V1 $(82.1$ $\pm 2.6 \%$; $p<0.05$; Figure $3 \mathrm{~L})$. There was a subsequent reduction in the proportion of DJ-1-positive neurons with increasing age (e.g., $18 \mathrm{~m}$; S1, $45.1 \pm 19.8 \%, p<0.05 ; \mathrm{V} 1,52.2 \pm 12.4 \%$, $p<0.05)$ compared to P0. There were no differences in the proportions of DJ-1-positive neurons between the adult ages (i.e., $6 \mathrm{~m}, 12 \mathrm{~m}$ ) and cortical regions. The costaining of DJ-1 and NF200-positive neurons was then unchanged between the adult ages (e.g., $18 \mathrm{~m}$ ) and P30m in the S1 $(34.4 \pm 10.6 \%, p=0.3)$, while an increase in the proportion of colabeled cells was found in the V1 $(75.9 \pm 9.7 \%, p<0.05)$ compared to adult stages of age (e.g., $18 \mathrm{~m}$ ) (Figures 3M-T).

\section{Glial staining}

Noticeable costaining of DJ-1 and GFAP-positive glial cells was detected in both the $\mathrm{S} 1(81.9 \pm 7.4 \%)$ and V1 $(67.6 \pm 3.9 \%$, $p<0.05)$ at $\mathrm{P} 0$ (Figures 3U-Y). However, there was a reduction in this association in both cortical areas at $6 \mathrm{~m}(\mathrm{~S} 1,23.7 \pm 10.1 \%$, $p<0.05$; V1, $12.8 \pm 7.5 \%, p<0.05)$, followed by an increase, beginning in the $\mathrm{S} 1$ at P30m (18 m: $19.8 \pm 10 \%, p<0.05$; P30m: $70.4 \pm 0.1, p=0.11)$ and in the V1 at $12 \mathrm{~m}(12 \mathrm{~m}: 28.8 \pm 6.4 \%$, $p<0.05$; 18 m: $54 \pm 6.8 \%, p<0.05$; P30m: $77.8 \pm 7.9 \%, p=0.07)$ compared to P0 (Figures 3U-Y).

\section{Microglial staining}

In contrast to the rare colabeling of DJ-1 and OX-42-positive microglial cells in both the S1 $(24.5 \pm 6.4 \%)$ and V1 $(31.4 \pm$ $6.4 \%$ ) observed at P0 (Figure 3Z), a strong increase was detected at advanced ages, such as $30 \mathrm{~m}(\mathrm{~S} 1,85.2 \pm 3 \%, p<0.05 ; \mathrm{V} 1,90.9$ $\pm 7.3 \%, p<0.05$ ) (Figures 3Z,AA-AD).

\section{STATHMIN}

\section{Protein expression levels}

WB analysis revealed expression of STMN in both cortical regions at $\mathrm{P} 0$, with a massive decrease at $6 \mathrm{~m}(\mathrm{~S} 1,2.5 \pm 0.7 \%, p<0.05$; $\mathrm{V} 1,2.5 \pm 3.5 \%, p<0.05), 12 \mathrm{~m}(\mathrm{~S} 1,3.9 \pm 1.3 \%, p<0.05 ; \mathrm{V} 1$, $2.8 \pm 3.9 \%, p<0.05), 18 \mathrm{~m}(\mathrm{~S} 1,3.8 \pm 1.3 \%, p<0.05 ; \mathrm{V} 1,3.6 \pm$ $5.1 \%, p<0.05)$, and $30 \mathrm{~m}(\mathrm{~S} 1,3.5 \pm 0.5 \%, p<0.05 ; \mathrm{V} 1,5.0 \pm$ $7.1 \%, p<0.05$ ) (Figures 4A,B).

\section{mRNA expression levels}

mRNA was significantly down-regulated at $6 \mathrm{~m}(\mathrm{~S} 1, \mathrm{RQ}=0.11$ $\pm 0.02, p<0.05 ; \mathrm{V} 1, \mathrm{RQ}=0.10 \pm 0.04, p<0.05), 12 \mathrm{~m}(\mathrm{~S} 1$, $\mathrm{RQ}=0.14 \pm 0.01, p<0.05 ; \mathrm{V} 1, \mathrm{RQ}=0.11 \pm 0.0001, p<0.05)$, $18 \mathrm{~m}(\mathrm{~S} 1, \mathrm{RQ}=0.12 \pm 0.002, p<0.05 ; \mathrm{V} 1, \mathrm{RQ}=0.07 \pm 0.02$, $p<0.05)$, and $30 \mathrm{~m}(\mathrm{~S} 1, \mathrm{RQ}=0.11 \pm 0.004, p<0.05$; V1, $\mathrm{RQ}=0.10 \pm 0.01, p<0.05)$ compared to P0 in both the S1 and V1 (Figure 4C). The data show a comparable age-related alterations in both the protein expression and mRNA levels of STMN in the S1 and V1.

\section{Immunohistochemistry}

The focus of STMN expression was in neuronal cells at the neonatal stage of age and in mircoglial cells at elderly stage of age. 

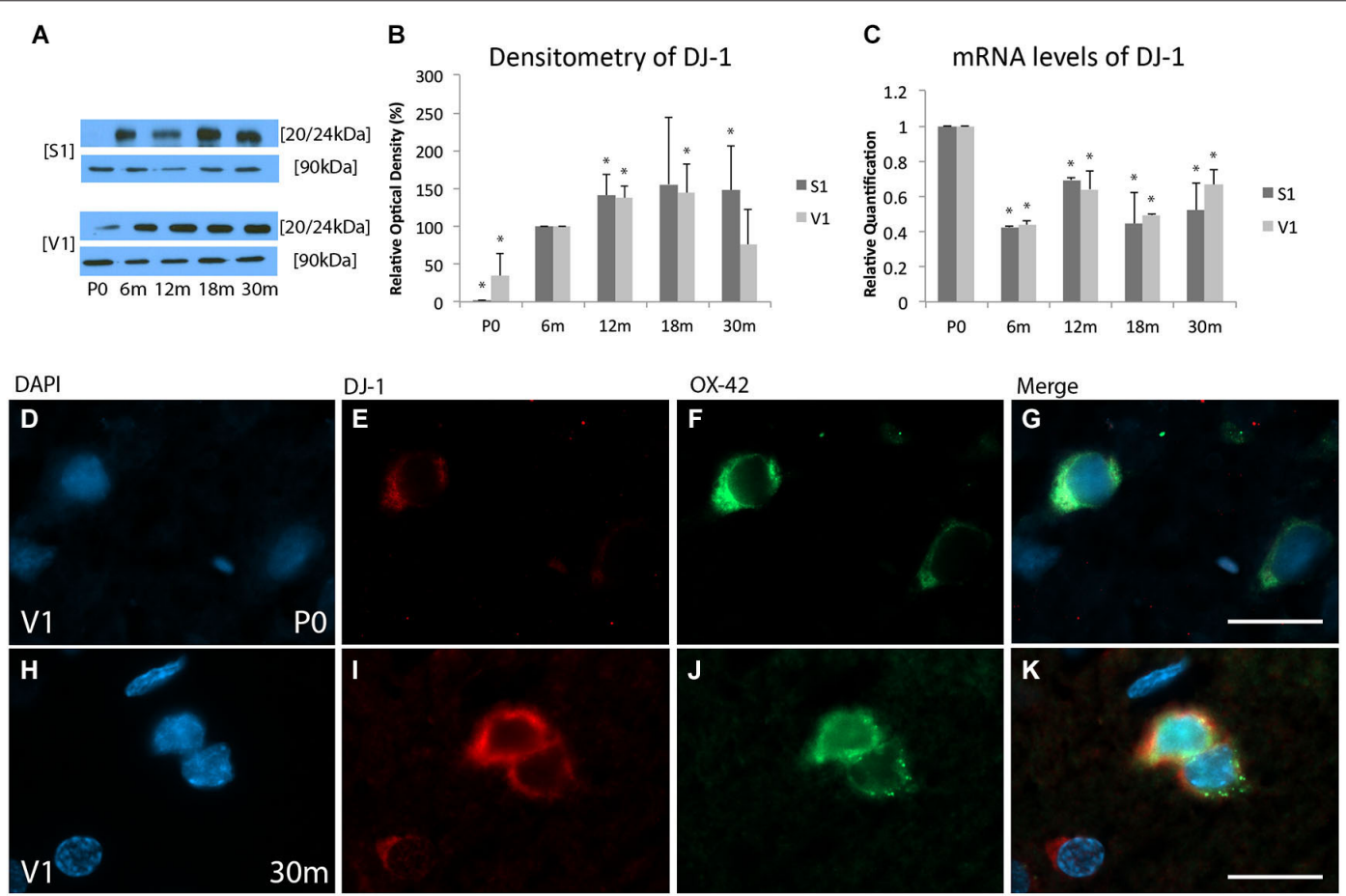

L

DJ-1+ / NF-200+ cortical cells
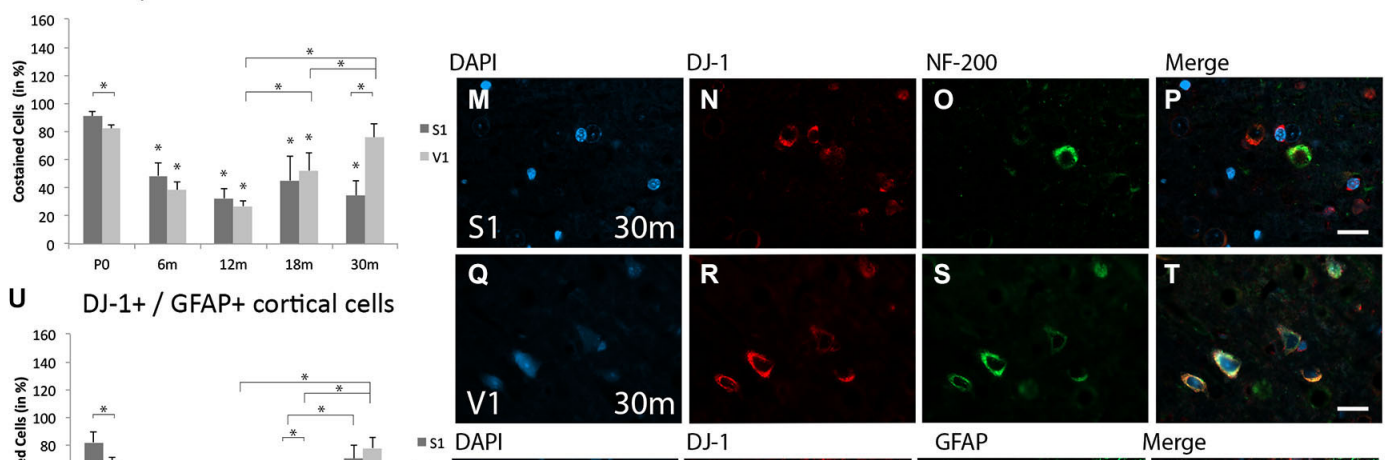

$\mathrm{U}$

DJ-1+ / GFAP+ cortical cells

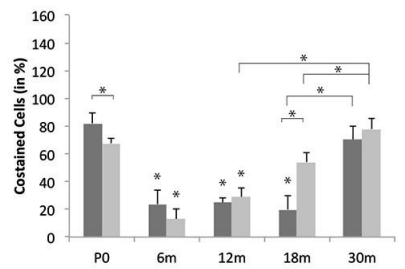

$\mathbf{Z}$

DJ-1+ / OX-42+ cortical cells
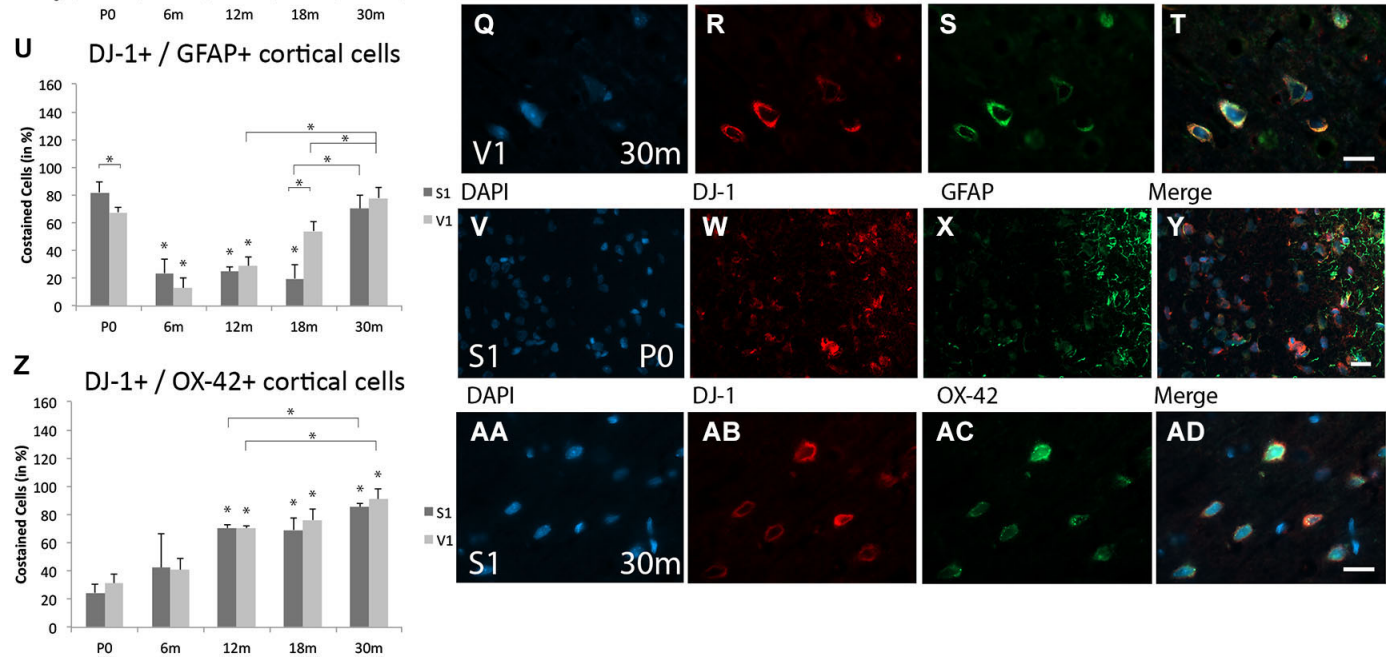

FIGURE 3 | Age-related expression and regulation of PARK[Parkinson disease (autosomal recessive, early onset)]7/DJ-1 (DJ-1) in the rat S1 and V1. (A) Western-blot analyses of cortex and (B) corresponding densitometric analyses of the Western-blot results relative to those measured at $6 \mathrm{~m}$ (in \%). Lysates of cortex treated as described in the main text were prepared and tested for DJ-1 (20/24 kDa) expression. Calnexin expression verified the amount of protein loaded per lane. Protein bands are given in kilodaltons. (C) Quantitative reverse-transcription polymerase chain reaction (qRT-PCR) results for DJ-1 mRNA levels relative to those measured at
P0. Expression of cortical DJ-1 (red) and several cortical cell types (green) revealed by immunohistochemical staining of $4-\mu \mathrm{m}$-thick sections of brain samples. (D-K) The intra- and extracellular localizations of DJ-1 in neonatal (P0) and 30 months ( $30 \mathrm{~m}$ ) aged $\mathrm{V} 1$ is shown in OX-42-positive microglial cells at higher magnification $(\times 63)$. Costaining rate of DJ-1 is shown in different cortical cell types: (L-T) Association between DJ-1 and NF-200-positive neuronal cells is demonstrated at $30 \mathrm{~m}$ in S1 and V1. (U-Y) Costaining of DJ-1 and GFAP-positive glial cells was performed in S1 at P0. (Z,AA-AD)

(Continued) 


\section{FIGURE 3 | Continued}

Colabeling of DJ-1 and OX-42-positive microglial cells is shown in S1 at P30m. The negative control was performed with Cy-2 and TRITC as secondary antibodies (data not shown). DAPI was used to stain the cell nuclei. Scale bars: (D-K), $10 \mu \mathrm{m}$; (M-P), (Q-T), (V-Y), and (AA-AD),

$20 \mu \mathrm{m}$. * Statistically significant difference at $p<0.05$; * standing by itself mean statistically significant differences in relation to $\mathbf{( B )} 6 \mathrm{~m}$ and $\mathbf{( C ,} \mathbf{L}, \mathbf{U}, \mathbf{Z})$ PO.

STMN was detected in close association with the nucleus in NF200-positive neuronal cells in both cortical regions (Figures 4D$\mathbf{K})$. In contrast, colabeling of STMN was found in the cytoplasm in both GFAP-positive cortical glial cells and OX-42-positive microglia.

\section{Neuronal staining}

STMN-positive neuronal cells were in found in neonatal rat cortices (S1, $89.1 \pm 7 \%$; V1, $88 \pm 6.6 \%$; Figures $4 \mathrm{~L}-\mathbf{P}$ ). Its colabeling rate decreased massively over life-time until late adulthood (e.g., $18 \mathrm{~m}$; S1, $13.7 \pm 3 \%, p<0.05$; V1, $13.7 \pm 4.5 \%$, $p<0.05)$ compared to P0. A decrease of these STMN-positive cells compared to P0 and adult stages $(12 \mathrm{~m}, 18 \mathrm{~m})$ was found in the $\mathrm{S} 1$ also in elderly stages (30 m: $4.9 \pm 2 \%, p<0.05)$. An increase in STMN staining in neuronal cells was detected in the V1 at P30m (35.8 $\pm 7.8 \%)$ compared to $18 \mathrm{~m}(40.2 \pm 6.2 \%, p<0.05)$ (Figure 4L).

\section{Glial staining}

A significant difference in colabeling of STMN and GFAP-positive glial cells was found in S1 $(30.1 \pm 8 \%)$ compared to V1 (88 \pm $6.6 \%, p<0.05$ ) at neonatal stages (Figures 4Q-U). A decrease in the proportion of the cells in which STMN and GFAP were costained in both the S1 $(9.5 \pm 4.5 \%, p<0.05)$ and V1 $(6.6$ $\pm 1.8 \%, p<0.0 .05)$ in the adult stages $(18 \mathrm{~m})$ compared to $\mathrm{P} 0$. At P30m, the proportion of STMN-positive glia cells show a tendency to increase in the S1 $(24.7 \pm 10 \%, p=0.5)$ compared to $\mathrm{P0}$ (Figures $4 \mathrm{Q}, \mathrm{V}-\mathrm{Y}$ ). A further decrease in the colabeling rate of STMN with GFAP-positive glial cells was found in the V1 ( $6 \pm$ $1.9 \%, p<0.05$ ) compared to P0.

\section{Microglial staining}

Noticeable colabeling of STMN and OX-42-positive microcglial cells was detected in both S1 (46.6 $\pm 10.9 \%)$ and V1 $(23.1 \pm 5.2 \%$, $p<0.05$ ) at P0 (Figure 4Z). The proportion of STMN-positive microglial cells remained unchanged in the S1 until the elderly stage of age (e.g., $30 \mathrm{~m}: 54.5 \pm 9.5 \%, p=0.4$ ), with exception of early adulthood (12 m: $62.6 \pm 11.6 \%)$ compared to advanced adult stages of age (18 m: $37.6 \pm 13.7 \%, p<0.05)$ (Figures 4AA$\mathrm{AD})$. In contrast, an increase of proportion of costaining was observed in the V1 $(6 \mathrm{~m}: 43.4 \pm 6 \%, p<0.05 ; 18 \mathrm{~m}: 40.2 \pm$ $6.1 \%, p<0.05 ; 30 \mathrm{~m}: 62.1 \pm 11.7 \%, p<0.05)$ compared to $\mathrm{P} 0$ (Figure 4Z).

\section{DISCUSSION}

We examined the expression of Prx, SNCB, DJ-1 and STMN during the postnatal maturation and aging in two areas (S1 and V1) of the cerebral cortex in rats (Böhm et al., 2013). Although the work presented here, including quantitative approaches toward the protein expression has limitations, to the best of our knowledge this has not been done previously and this is the first study to describe the expression of these age-related proteins in morphologically and functionally different cortical regions. The principal findings of the study are as follows:

1. The $S 1$ and V1 share in common the postnatal maturation and age-related proteins Prx, SNCB, DJ-1, and STMN, which have previously been described in the retina.

2. Pyramidal neurons and glial cells exhibit a decrease in Prx expression in both the S1 and V1 in an age-related context.

3. SNCB expression increased in V1 pyramidal neurons during adulthood, whereas it remained unchanged over life-time in the S1.

4. DJ-1 expression decreased continuously in the S1 pyramidal neurons during the measured life-time, whereas its expression increased to neonatal levels in the elderly V1.

5. A massive reduction in STMN expression has been found in neuronal cells and glial cells in both the S1 and V1.

Studies in the last decades regarding cortical development and aging have been performed mainly with tissue obtained from human and nonhuman primates (Huttenlocher, 1990; Rakic et al., 1994; Elston and Rosa, 2006; Bianchi et al., 2013; Oga et al., 2013). Few of these studies have revealed differences in the cortical development of rodents compared to primates, although marked differences have been demonstrated in pyramidal cell structure in homologous cortical areas between primates and rodents (Elston and Manger, 2014). Studies comparing mouse, rhesus macaque monkey, and human brains have revealed divergence in the expression patterns of major genes (Loerch et al., 2008). For example, up-regulation of genes participating in neuronal functions was found during aging in mice, but these genes were down-regulated during aging in humans. Given the assumption of an evolutionary shift between the lineage of rodents and humans, this finding may be attributed to specific human neurodegenerative disorders such as $\mathrm{AD}$. The data presented in this study were assessed using the brains of Sprague-Dawley rats. These laboratory animals are easy to access and provide "comparable" life events due to their short lifespan relative to humans. Moreover, the quantification of the subset of cortical cells was performed with semi quantitative methods and not with high-performance stereological methods. Nevertheless, interesting alterations in the protein expression in rats due to development and aging were detected in the selected cortical regions. We will briefly review what is already known in rodents, humans and nonhumans. Then, we will discuss in detail the selected proteins and regional differences in their patterns of expression in the two cortical areas of interest.

Genetic and epigenetic assumptions, area-specific factors, and the function of its projections influence pyramidal cell structure and create regional variations in pyramidal cell phenotypes in the primate cerebral cortex (Vercelli and Innocenti, 1993; Elston et al., 1996, 2011a; Matsubara et al., 1996; Elston and Rosa, 1997, 1998, 2006; Elston, 2000; Jacobs et al., 2001; Elston and Rockland, 2002; Benavides-Piccione et al., 2006; Bianchi et al., 2013; Oga et al., 2013; Sasaki et al., 2014). A physiological 

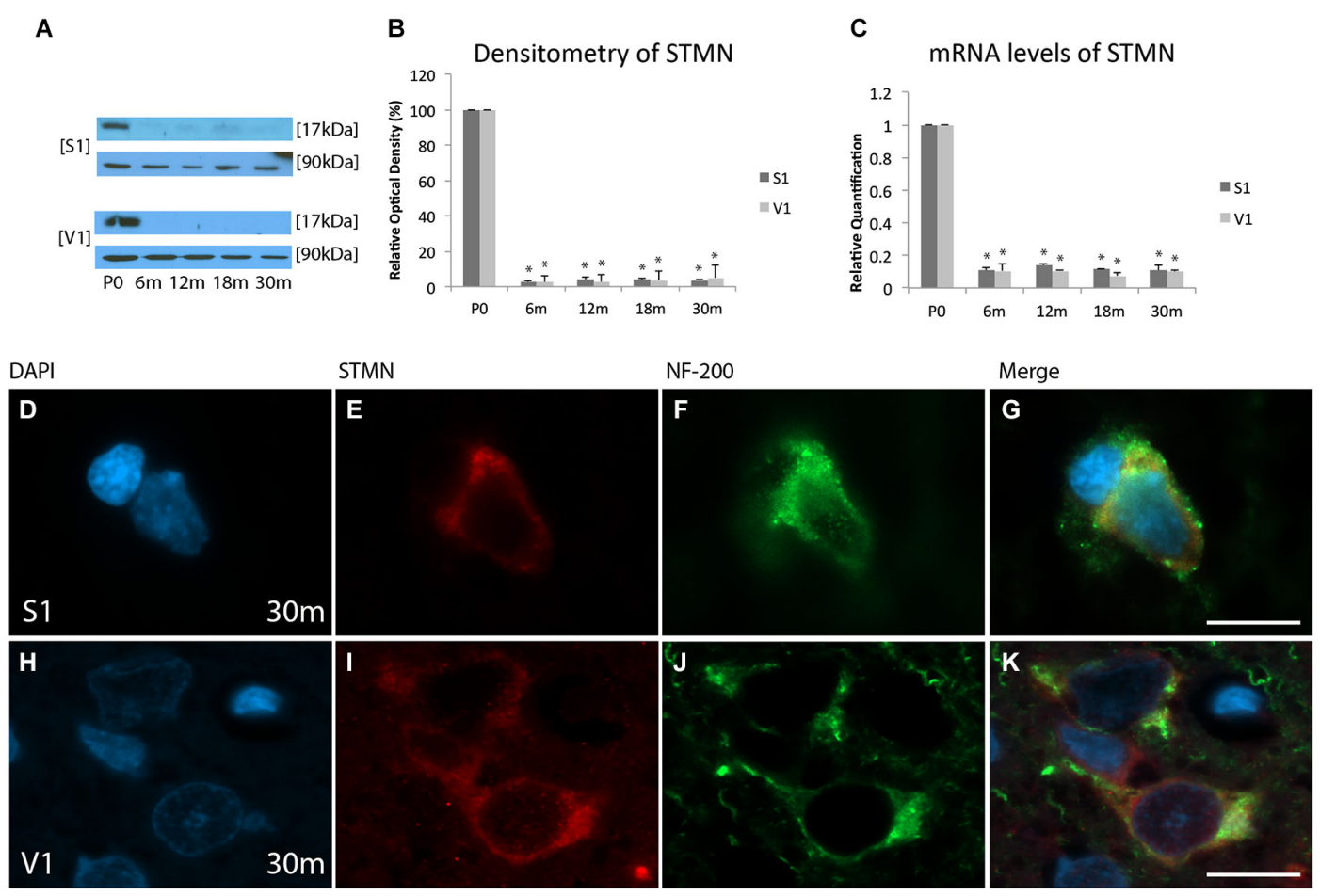

L STMN+/ NF-200+ cortical cells

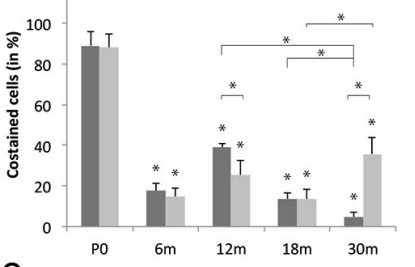

Q STMN+/GFAP+ cortical cells

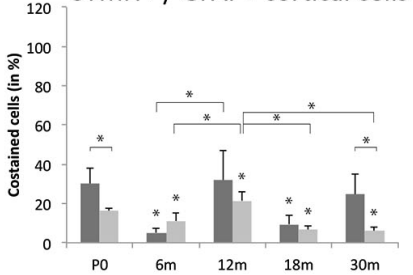

Z STMN+/OX-42+ cortical cells
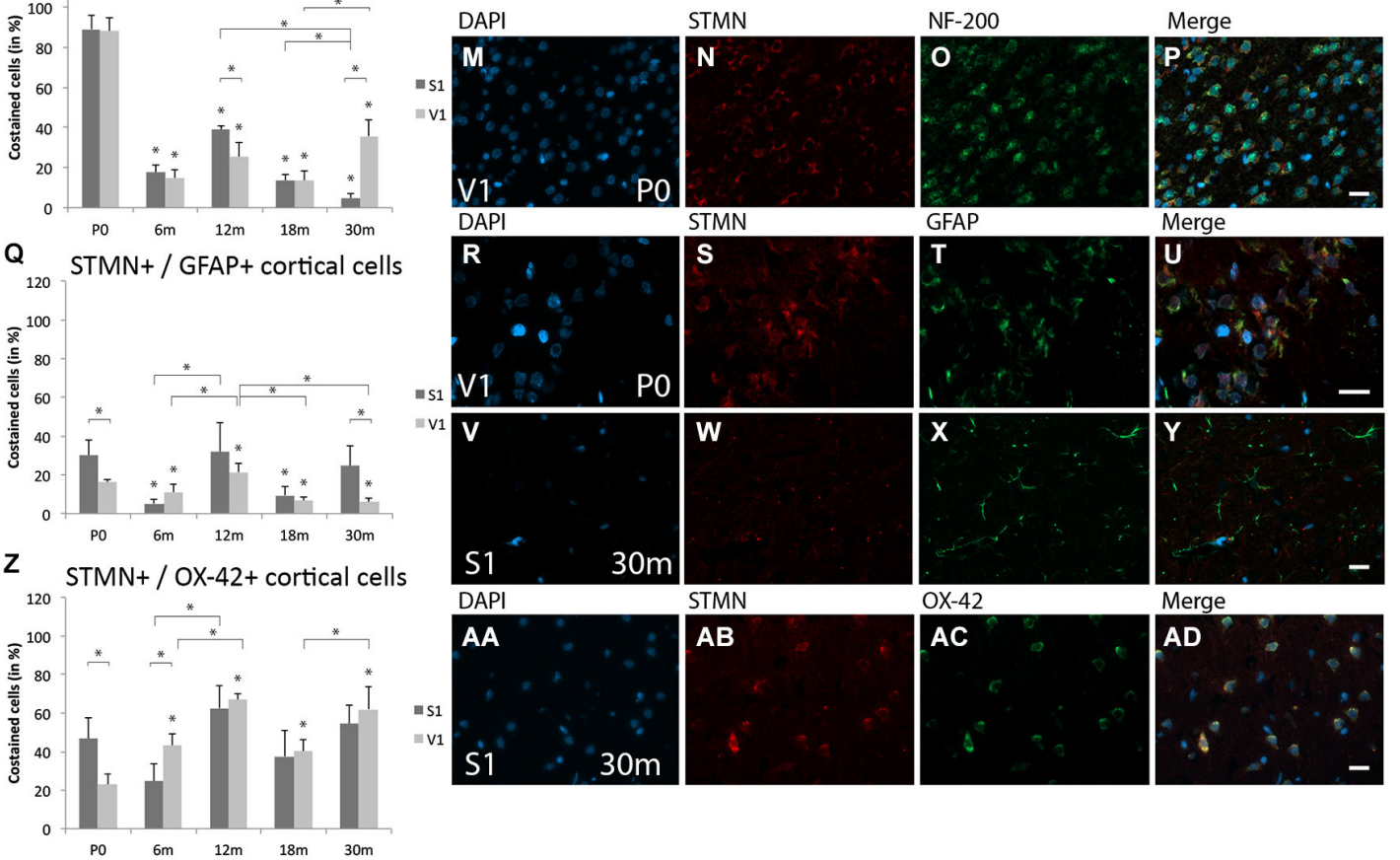

FIGURE 4 | Age-related expression and regulation of stathmin (STMN) in the rat S1 and V1. (A) Western-blot analyses of retinas and

(B) corresponding densitometric analyses of the Western-blot results relative to those measured at P0 (in \%). Lysates of cortex treated as described in the main text were prepared and tested for STMN (17 kDa) expression. Calnexin expression verified the amount of protein loaded per lane. Protein bands are given in kilodaltons. (C) qRT-PCR results of STMN mRNA levels relative to those measured at PO. Expression of cortical STMN (red) and several cortical

cell types (green) revealed by immunohistochemical staining of $4-\mu \mathrm{m}$-thick sections of brain samples. (D-K) Intra- and extracellular localizations of STMN (red) were detected in aged S1 and V1 in NF-200-positive cells (green) at higher magnification $(\times 63)$. Costaining rate of STMN is shown in different cortical cell types: (L-P) Costaining of STMN is shown at PO with NF-200-positive neuronal cells in the V1. (Q-Y) Association of STMN with GFAP-positive glial cells is demonstrated in V1 at P0 and S1 at P30.

(Continued) 


\section{FIGURE 4 | Continued}

(Z,AA-AD) Colabeling of STMN with OX-42 is shown in $\mathrm{S} 1$ at $30 \mathrm{~m}$. The negative control was performed with $\mathrm{Cy}-2$ and TRITC as secondary antibodies (data not shown). DAPI was used to stain the cell nuclei. Scale bars: (D-K), $10 \mu \mathrm{m}$; (M-P), (R-U), (V-Y), and (AA-AD), $20 \mu \mathrm{m}$.

*Statistically significant difference at $p<0.05$; * standing by itself mean statistically significant differences in relation to $\mathrm{PO}$. loss of neuronal cells and synapses is likely caused by a failure of developing neurons to find targets for innervation. This observation is missing in complex neuronal systems such as the human neocortex, whereas a 30\% loss of cortical neurons has been observed in rodents (e.g., in the mouse) (Heumann et al., 1978; Heumann and Leuba, 1983). There is also little evidence for overproduction of synapses in rodents, and the synaptic density in the rat brain reaches a maximum at about postnatal day 35, which is less than $10 \%$ greater than in the adult (Aghajanian and Bloom, 1967). During the first postnatal month in cats, glial cells may influence the development of axons, and both microglial and astrocytes participate in the shaping of the callosal cortical maps to the level of the V1 in mammals (Rochefort et al., 2002).

Physiological aging in the mammalian brain is characterized by several interrelated morphological and metabolic changes. Recent morphological studies have revealed considerable variations in different parts of the brain, including the human cerebellum and the cerebral cortex of rhesus monkeys (Nandy, 1981). Physiological aging is not associated with significant neuronal loss in the human or macaque neocortex (Peters et al., 1994; Pakkenberg and Gundersen, 1997). Instead, agerelated cognitive decline is thought to result from more subtle synaptic alterations (Morrison and Hof, 1997). Qualitative observations of dendritic spine reduction have been made in the aging cortex of humans, nonhuman primates, mice and rats, which are consistent with reports of age-related decreases in synapses in different cortical regions (Lee et al., 2000; Fraser et al., 2005; Yankner et al., 2008; Stranahan et al., 2012).

Age-related metabolic changes include a global reduction in the brain's energy requirements and decreases in cerebral blood flow and glucose utilization (Chugani et al., 1991). Recent studies exploring age-related changes in dendrites and dendritic spines in the frontopolar and occipital regions of the human neocortex indicate that different cortical areas in primates do not age in a uniform manner. For example, the prefrontal cortex appears to be more susceptible to aging than sensory regions such as the occipital cortex (Azari et al., 1992; Eberling et al., 1995; Jacobs et al., 1997). The prefrontal cortex exhibits a higher metabolism and regional cerebral blood flow in the normal (resting) state than other cortical areas (Roland, 1984). Life-time changes in cortical metabolism parallel the age-related variations in synaptic densities observed in the frontal cortex (e.g., S1), but they correlate less with changes in synaptic density in the V1 (Jacobs et al., 1997). Aging is also a risk factor for progressive brain disorders in which neuroinflammation plays a prominent role. Coordinated changes in gene transcription cascades underlie changes in synaptic, neurotrophic, and inflammatory phenotypic networks during brain development, maturation and aging. Early postnatal changes in gene expression are related to neuronal, glial, and myelin growth, and synaptic pruning events, while late aging is associated with proinflammatory and synaptic loss (Primiani et al., 2014). Thus, the distribution and morphology of astrocytes and microglial cells changes with age (Rochefort et al., 2002).

\section{PEROXIREDOXIN}

Prx was expressed in both the rat S1 and V1 throughout the ages examined. In the present study, the protein levels of Prx did not change significantly in the rat cortex during aging, although a slight decrease in its mRNA was observed in both cortical regions. The expression of Prx have been recently studied in the human, murine, and (in the case of Prx-1) rat brain (Sarafian et al., 1999; Mizusawa et al., 2000; Wang et al., 2003). Prx are presumably involved in various cellular reactions, such as cellular defense against reactive oxygen species (ROS), receptor signaling, gene regulation, and apoptosis (Jim and Jeang, 1999; Singh and Shichi, 2001). They are functioning mainly to support cells, including oligodendrocytes and Schwann cells, probably protecting them against oxidative stress (Mizusawa et al., 2000). Prx-1 is associated with glial cells, and particularly with oligodendrocytes and neurons (Mizusawa et al., 2000; AonBertolino et al., 2011). Prx-2, -3, -4, and -5 have been detected in projection neurons in the human brain (Sarafian et al., 1999; AonBertolino et al., 2011). Loss of mitochondria in CA1 pyramidal neurons has been detected in Prx-2-defcient mice due to the functioning of the extracellular signaling kinases pathway (Kim et al., 2011). Neuroglial localization of Prx-6 has been detected in mouse and human brains (Wang et al., 2003; Aon-Bertolino et al., 2011), with a high degree of specificity for this cell type.

An age-dependent diversification of the cell types expressing Prx was detected. An association between Prx and neuronal, glial, and microglial cells was found in both the S1 and V1 of the neonatal rat brain. A reduction in Prx labeling of both neuronal and glial cells during aging suggests a loss of mechanisms for responding to oxidative stress in major cell types in the cortex. The age-related changes in the expression of Prx and the associated cell types detected in the present study are probably associated with changes in the vulnerability of cortical neurons to oxidative stress. Brain samples from elderly individuals have revealed decreased Prx-2 protein levels, which may induce increased oxidative stress in the aging brain (Chen et al., 2003; Aon-Bertolino et al., 2011). Decreased Prx-3 expression was detected in regions known to be specially affected in AD, Down's syndrome, and PD (Kim et al., 2001; Krapfenbauer et al., 2003). We observed a decrease in Prx expression in pyramidal cortical cells in the V1 after 6 months of life, compared to a decrease after 12 months in the S1. This finding could be associated with the reported slower progress of dendritic development and increase in synaptic density in the S1 compared to the V1 (Huttenlocher and Dabholkar, 1997; Jacobs et al., 1997).

The increase of microglial cells positive stained for Prx during aging suggests an increased activation of immunoassociated cell 
types in the cortical regions. This observation concurs with the reported neuronal loss of up to $30 \%$ and overproduction of synapses during rodent brain maturation between birth and adulthood. These changes roughly parallel the age-related variations in synaptic densities observed in the S1, but are less well correlated with changes in synaptic density in the primary V1 (Heumann et al., 1978; Heumann and Leuba, 1983; Huttenlocher and Dabholkar, 1997). Moreover, an earlier increase in the proportion of Prx-positive microglial cells was found in the V1 compared to the S1, where this increase in microglial Prx staining began in the adult ages. The diversity of Prx-positive pyramidal cells and microglia in different cortical areas may reflect this difference in metabolic demand, including metabolic and oxygen stress in the S1 and V1.

Comparison of Prx expression relative to subsets of brain cells revealed a shift from neurons and glia toward microglia. However, comparison between the areas examined revealed that the expression and colabeling profiles were not comparable between the two, suggesting that the proteins show aspects of known cortical development steps reflecting regional features. A sole association with visual processing cannot be concluded. The uniform expression of Prx over the frontal and occipital lobes may be associated with the vulnerability of the brain to oxidative stress in comparison to other organs due to its high oxygen utilization, high iron content, presence of unsaturated fatty acids, and reduced activities of detoxifying enzymes such as superoxide dismutase, catalase, and glutaredoxins (Dringen, 2000; Capani et al., 2001; Rodríguez et al., 2005). The disturbance of redox homeostasis, low levels of glutathione, and increased production of ROS and peroxynitrite have been described for several CNS disorders, such as perinatal asphyxia (Capani et al., 2001), stroke (Eliasson et al., 1999), focal traumatic brain injury (Singh et al., 2006), and numerous neurodegenerative disorders including $\mathrm{AD}, \mathrm{PD}$, multiple sclerosis, and amyotrophic lateral sclerosis (Bains and Shaw, 1997; Torreilles et al., 1999). Lastly, the localization of Prx in neuronal cells in neonatal, and microglial cells in aged cortical regions concurs with the localization reported in the aging retina (Böhm et al., 2013).

\section{BETA-SYNUCLEIN}

We detected an increase expression of SNCB within both the S1 and V1 over the life-time of rats. The family of cytoplasmic synuclein proteins that comprises SNCA, SNCB, and gamma-synuclein (SNCG) is thought to function in synaptic vesicles and neurotransmission, and neuronal plasticity. SNCA and SNCB are highly homologous proteins, and are colocalized in presynaptic nerve terminals in the CNS. In contrast, SNCG is expressed primarily in the PNS (Hashimoto et al., 2001; Sung and Eliezer, 2007). SNCB may elicit neuroprotective functions, e.g., the neurotoxic response in 6hydroxydopmaine-affected TSM-1 (twin sensillum of margin 1) neurons (Hashimoto et al., 2001, 2004; Park and Lansbury, 2003; Tsigelny et al., 2007). It has been shown that SNCB decreases the proapoptotic gene p53 (da Costa et al., 2003). Furthermore, SNCB activates the Akt signaling pathway in rotenone-affected tissue culture B103 cells (Hashimoto et al.,
2004). Hashimoto suggested that the SNCB activation of Akt resulted in Mdm2 (mouse double minute 2 homolog) phosphorylation, which in turn inactivates $p 53$. This mechanism may promote neuroprotection against toxins (Hashimoto et al., 2004). Finally, SNCB protects the CNS against the toxic effects of SNCA overexpression in $t g$ mice (Spillantini et al., 1997), in which SNCB overexpression results in increased Akt pathway activity, suggesting that the phosphatidylinositide-3kinase signaling pathway is a potential therapeutic target for PD via SNCA aggregation.

The expression pattern of SNCB varied considerably in the rat cortices throughout the life-time. It was expressed in both the $\mathrm{V} 1$ and S1, beginning at $6 \mathrm{~m}$. In contrast to S1, early expression of SNCB was detected in the neonatal V1. In neonatal cortices, SNCB was detected in close association with neuronal and glial cells; it was less clearly correlated with microglial cells. The increased SNCB expression after birth may reflect the fact that the synaptic density in the rat brain reaches a maximum at about postnatal day 35, which is only less than $10 \%$ greater than the adult value (Aghajanian and Bloom, 1967). As yet we have no direct explanation for the early expression of SNCB in the V1. It may be associated with the increased requirements for early postnatal maturation in the S1 in contrast to the sparsely developed neonatal visual system of rats.

An age-related divergence in the increase in SNCB-positive pyramidal cells was found in both adult rat cortices in this study (i.e., S1 and V1). An increased association between SNCB and pyramidal neurons was found in V1 beginning at the adult stage of life. In contrast, the S1 exhibited mainly SNCB colocalized with NF-200-positive neuronal cells in the elderly rats. We presume that the earlier increase in SNCB expression by pyramidal neurons could reflect the lower vulnerability of the V1 to aging in contrast to the sensory cortex, possibly due to the reported association with a higher metabolic rate and regional blood flow in the S1.

We found comparable levels of SNCB expression in the S1 and $\mathrm{V} 1$ and in the aging retina (Böhm et al., 2013). In contrast to the strong association with the synapse-rich retinal layers, SNCB in the cortex appeared to be associated with neonatal neuronal cells and aged glial cells.

\section{DJ-1}

DJ-1 is expressed in many tissues, including the brain without any preference to a single functional system or anatomical area (Nagakubo et al., 1997; Bader et al., 2005). In this study, DJ-1 expression was found in both the V1 and S1 throughout the life-time of rats. In the V1 DJ-1 expression increased up to the late adult age and then regressed to neonatal levels, that in the S1 increased continuously from P0 to the senile age stages. DJ-1 plays a cardinal role in maintaining mitochondrial function and is reported to possess neuroprotective properties by limiting oxidative damage (Moore et al., 2005). DJ-1 can enhance antioxidant systems and promote antioxidant mechanisms (Liu et al., 2008; Blackinton et al., 2009). Moreover, it is involved in the functioning of the ubiquitin-proteasome system, which reduces the accumulation of toxic protein substrates. Mitochondrial dysfunction (and the associated oxidative stress) and altered functioning of the ubiquitin-proteasome system are 
considered important factors in familial and sporadic forms of PD. Importantly, it is widely accepted that impairments of these mechanisms are common denominators of neurological disorders in general, and in particular AD and multiple sclerosis, and may already have occurred in the early stages of these diseases (Moreira et al., 2005; Lassmann and van Horssen, 2011; van Horssen et al., 2011; Wilhelmus et al., 2012). Neverless, DJ-1 may operate at the intersection of environmental stressors and aging (Chen et al., 2014).

DJ-1 is expressed in neurons with different neurotransmitters and in all glial cell types, such as astrocytes, microglia and oligodendrocytes. In a number of cell lines, DJ-1 is associated with microtubules and localizes to both the nucleus and the cytoplasm (Hod et al., 1999; Bader et al., 2005). The neuronal and synaptic expressions of DJ-1 in primate subcortical brain regions suggest a physiological role for DJ-1 in the survival and/or function of nigrostriatal neurons (Olzmann et al., 2007). The expression characteristics of DJ-1 in pyramidal neurons reported herein for the $\mathrm{S} 1$ and $\mathrm{V} 1$ are comparable to other examined stress-related proteins, like Prx. The proportion of DJ-1 in NF-200 positive neurons decreased gradually from the day of birth with aging in the S1, whereas it increased to adulthood in the V1. The loss of associated DJ-1 in neuronal cells may indicate a loss of protective factors in the aging brain. A reduced expression of DJ1 in glial cells was found in both of the cortical areas examined in young adulthood compared to older brains. Recent studies described the abundantly-expression of DJ-1 in PD astrocytes (Bandopadhyay et al., 2004; Neumann et al., 2004; Rizzu et al., 2004; Mullett et al., 2009). This may represent an attempt by astrocytes to protect themselves, and surrounding neurons, against disease progression. DJ-1 is over-expressed in astrocytes enhancing their neuroprotective capacity against rotenone and other pesticides in vitro. DJ-1 knock-down astrocytes were impaired in this capacity. DJ-1 modulate the release of soluble factors by astrocytes (Mullett and Hinkle, 2009, 2011). The prevalence of DJ-1 expression in microglia increased with aging in both the S1 and V1. DJ-1-deficient microglia had increased monoamine oxidase (MAO) activity that resulted in elevation levels of neurotoxic secreted factors, including intracellular ROS, nitric oxide, and pro-inflammatory cytokines (Trudler et al., 2014). These findings suggest an increased association between DJ-1 expression and cells associated with the innate immune system in the cortex.

The localization of DJ-1 in the retina also varies over life-time. In newborn rats, DJ-1 has been found in the germinative ganglion cell layer, and after P16 and marginally at P23 and P60 in the inner plexiform layer (Böhm et al., 2013). Although the exact role of DJ-1 in the retina is not clear, its main role may be in the early retinal maturation (Haniu et al., 2006; Finnegan et al., 2008). However, these data indicate comparable expressions of DJ-1 in visual-specific neuronal regions during aging.

Given the role of DJ-1 in maintaining mitochondrial function and reducing oxidative stress, this pattern of expression may reflect the lower vulnerability of the V1 to aging and oxidative stress compared to the $\mathrm{S} 1$. The presented findings reveal a difference in the expression of DJ-1 in various cortical regions and cortical cell types show over the life-time in rats.

\section{STATHMIN}

Our data show a dramatic decrease in STMN in both the S1 and V1 beginning at $6 \mathrm{~m}$; thereafter, the expression of STMN remained stably low until $30 \mathrm{~m}$. These observations are in general agreement with previous studies, which have found STMN in the late embryonic and early postnatal phase of cerebral development. During rat development, the highest expression of stathmin family proteins is from late embryogenesis until a week after birth, when dendrite formation, axon guidance and synaptic in the developing CNS are most dynamic and has mainly found in the cortex and nucleus accumbens (Ozon et al., 1999; Hayashi et al., 2006). Proteins of the stathmin family proteins are expressed in different cell populations, including neurons and glial cells (Ozon et al., 1999; Charbaut et al., 2001). Stathmin has been implicated in growth, differentiation and cell cycle control (Sobel, 1991; Schubart et al., 1996). Stathmin is involved in neural development, differentiation, plasticity, learning, degeneration and aging (Mori and Morii, 2002; Nelson et al., 2004). These studies are in agreement with the neonatal findings of this study, that STMN was mainly found in NF200-positive neuronal cells. Protein and mRNA levels of STMN have also been found in the developing, maturating, and adult CNS in several species, including chicken, mouse, rat and in post-mortem human brains from schizophrenia and $\mathrm{AD}$ patients (Ozon et al., 1999; Hayashi et al., 2006; Finnegan et al., 2008). A decrease of forced expression of stathmin in response to lesioning of the adult rat cortex has been found with age (Hayashi et al., 2006). This may be in accordance to the findings of a massive decreased association between STMN and pyramidal neurons in both the $\mathrm{S} 1$ and V1 together with a decrease of neuronal plasticity during life-time until elderly stages of age (Hayashi et al., 2006).

Recent studies indicate a regulatory role of STMN during inflammtation and repair in the adult CNS (Bsibsi et al., 2010). Shen et al. reported about a activated serine-threonine kinase interacting stathmin (KIS) due to spinal cord injury, which interact and posporylate stathmin inducing cell cycle progression of glial cells, especially microglia and astrocytes (Petrovic et al., 2008; Shen et al., 2008). Further studies found a colocalization of stathmin with TLR3 on astrocytes, microglia, and neurons in multiple sclerosis-affected human brains (Bsibsi et al., 2010). Nigrostrial dopimergic neurodegeneration and the expression levels of STMN were significantly depentend on microglial activation (Singh et al., 2011). In the present study, an increase in STMN-positive microglial cells in V1 was found in contrast to unchanged costainings in the S1 over life-time. Taken together, the observations in the present study are probably in accordance with the less vulnerability of the V1 compared to S1 regarding to oxidative stress and aging. We recently described a strong expression of STMN in the neonatal rat retina, with a subsequent decrease during retinal maturation, and no expression after 2 months of life. During embryonic development and early maturation of the retina, STMN was found in both the IPL and OPL (Böhm et al., 2013). The expression profile of STMN appears to be correlated with neuronal differentiation and plasticity in the younger retina; its detection in the retinal plexiform layers in the mature retina might be correlated with ongoing 
synaptic plasticity in the adult tissue (Nakazawa et al., 2000). STMN expression in the aging S1 and V1 in the present study exhibited patterns that were comparable with that of the aging neuroretina. It appears that there is an almost identical agerelated regulation of STMN in the cortex and retina. To the best of our knowledge, the present study is the first to reveal an association between STMN and visual associated areas in the CNS.

\section{CONCLUSIONS}

The alterations of the detected proteins in both the retina and cortex may be associated with generalized mechanisms in postnatal development, maturation and aging. Distinct cortical areas were found in this study to exhibit differential patterns of expression of Prx, SNCB, DJ-1, and STMN. The alterations in Prx and DJ-1 with aging are likely associated with impairment of the oxidative-stress-regulating process. If a similar increase in SNCB expression also occurs over the life-time in the human brain, it may be related to neurodegenerative diseases such as AD. The massive reduction in STMN may be associated with loss of neuronal plasticity during CNS aging. Summarized in a comparative context, the age-related expression profile of proteins within the V1 appears to be similar to that in the retina. The results support the hypothesis of Elston, that developmental and maturation mechanisms and area-specific factors have a significant effect on the cell morphology of pyramidal neurons, the process of forming a neuronal network, and synaptic densities in different cortical areas (Elston, 2002, 2007). More over, the observed alterations in protein expression over life-time concurs with developmental, maturational and age-related changes in oxidative stress response, metaboblic impairments and loss of the neuronal network. Further studies are needed to confirm the protein changes reported herein in other species, and would contribute to a better understanding of the mechanisms underlying the senescence that may predict potential neurodegeneration.

\section{ACKNOWLEDGMENTS}

The authors thank M. Wissing and M. Langkamp-Flock for their skillful technical assistance, and Professor Dr. Arnd Heiligenhaus for comments that greatly improved the manuscript. The authors thank English Science Editing for native linguistic editing of the manuscript. This work was supported by an Innovative Medical Research (IMF) grant awarded by the School of Medicine, Westfalian-Wilhelms-University of Münster (IBö221307 to MRRB) and German Research foundation (DFG) grant (Th $386 / 20-1$ to ST).

\section{REFERENCES}

Aghajanian, G. K., and Bloom, F. E. (1967). The formation of synaptic junctions in developing rat brain: a quantitative electron microscopic study. Brain Res. 6, 716-727. doi: 10.1016/0006-8993(67)90128-x

Ahmad, A., and Spear, P. D. (1993). Effects of aging on the size, density and number of rhesus monkey lateral geniculate neurons. J. Comp. Neurol. 334, 631-643. doi: 10.1002/cne.903340410

Amatrudo, J. M., Weaver, C. M., Crimins, J. L., Hof, P. R., Rosene, D. L., and Luebke, J. I. (2012). Influence of highly distinctive structural properties on the excitability of pyramidal neurons in monkey visual and prefrontal cortices. $J$. Neurosci. 32, 13644-13660. doi: 10.1523/JNEUROSCI.2581-12.2012
Anderson, S. A., Classey, J. D., Condé, F., Lund, J. S., and Lewis, D. A. (1995). Synchronous development of pyramidal neuron dendritic spines and parvalbumin-immunoreactive chandelier neuron axon terminals in layer III of monkey prefrontal cortex. Neuroscience 67, 7-22. doi: 10.1016/03064522(95)00051-j

Andrews-Hanna, J. R., Snyder, A. Z., Vincent, J. L., Lustig, C., Head, D., Raichle, M. E., et al. (2007). Disruption of large-scale brain systems in advanced aging. Neuron 56, 924-935. doi: 10.1016/j.neuron.2007.10.038

Aon-Bertolino, M. L., Romero, J. I., Galeano, P., Holubiec, M., Badorrey, M. S., Saraceno, G. E., et al. (2011). Thioredoxin and glutaredoxin system proteinsimmunolocalization in the rat central nervous system. Biochim. Biophys. Acta 1810, 93-110. doi: 10.1016/j.bbagen.2010.06.011

Azari, N. P., Rapoport, S. I., Salerno, J. A., Grady, C. L., Gonzalez-Aviles, A., Schapiro, M. B., et al. (1992). Interregional correlations of resting cerebral glucose metabolism in old and young women. Brain Res. 589, 279-290. doi: 10. 1016/0006-8993(92)91288-p

Bader, V., Ran Zhu, X., Lubbert, H., and Stichel, C. C. (2005). Expression of DJ-1 in the adult mouse CNS. Brain Res. 1041, 102-111. doi: 10.1016/j.brainres.2005. 02.006

Bains, J. S., and Shaw, C. A. (1997). Neurodegenerative disorders in humans: the role of glutathione in oxidative stress-mediated neuronal death. Brain Res. Brain Res. Rev. 25, 335-358. doi: 10.1016/s0165-0173(97)00045-3

Balietti, M., Tamagnini, F., Fattoretti, P., Burattini, C., Casoli, T., Platano, D., et al. (2012). Impairments of synaptic plasticity in aged animals and in animal models of Alzheimer's disease. Rejuvenation Res. 15, 235-238. doi: 10.1089/rej.2012. 1318

Ballesteros-Yáñez, I., Benavides-Piccione, R., Elston, G. N., Yuste, R., and DeFelipe, J. (2006). Density and morphology of dendritic spines in mouse neocortex. Neuroscience 138, 403-409. doi: 10.1016/j.neuroscience.2005. 11.038

Bandopadhyay, R., Kingsbury, A. E., Cookson, M. R., Reid, A. R., Evans, I. M., Hope, A. D., et al. (2004). The expression of DJ-1 (PARK7) in normal human CNS and idiopathic Parkinson's disease. Brain. 127(Pt. 2), 420-430. doi: 10. 1093/brain/awh054

Benavides-Piccione, R., Ballesteros-Yáñez, I., DeFelipe, J., and Yuste, R. (2002). Cortical area and species differences in dendritic spine morphology. J. Neurocytol. 31, 337-346. doi: 10.1023/A:1024134312173

Benavides-Piccione, R., Hamzei-Sichani, F., Ballesteros-Yáñez, I., DeFelipe, J., and Yuste, R. (2006). Dendritic size of pyramidal neurons differs among mouse cortical regions. Cereb. Cortex 16, 990-1001. doi: 10.1093/cercor/ bhj041

Bianchi, S., Stimpson, C. D., Bauernfeind, A. L., Schapiro, S. J., Baze, W. B., McArthur, M. J., et al. (2013). Dendritic morphology of pyramidal neurons in the chimpanzee neocortex: regional specializations and comparison to humans. Cereb. Cortex 23, 2429-2436. doi: 10.1093/cercor/bhs239

Bishop, N. A., Lu, T., and Yankner, B. A. (2010). Neural mechanisms of ageing and cognitive decline. Nature 464, 529-535. doi: 10.1038/nature08983

Blackinton, J., Lakshminarasimhan, M., Thomas, K. J., Ahmad, R., Greggio, E., Raza, A. S., et al. (2009). Formation of a stabilized cysteine sulfinic acid is critical for the mitochondrial function of the parkinsonism protein DJ-1. J. Biol. Chem. 284, 6476-6485. doi: 10.1074/jbc.M806599200

Böhm, M. R., Mertsch, S., König, S., Spieker, T., and Thanos, S. (2013). Maculaless rat and macula-bearing monkey retinas exhibit common lifelong proteomic changes. Neurobiol. Aging 34, 2659-2675. doi: 10.1016/j.neurobiolaging.2013. 04.020

Bourgeois, J. P., and Rakic, P. (1993). Changes of synaptic density in the primary visual cortex of the macaque monkey from fetal to adult stage. J. Neurosci. 13, 2801-2820.

Bsibsi, M., Bajramovic, J. J., Vogt, M. H., van Duijvenvoorden, E., Baghat, A., Persoon-Deen, C., et al. (2010). The microtubule regulator stathmin is an endogenous protein agonist for TLR3. J. Immunol. 184, 6929-6937. doi: 10. 4049/jimmunol.0902419

Capani, F., Loidl, C. F., Aguirre, F., Piehl, L., Facorro, G., Hager, A., et al. (2001). Changes in reactive oxygen species (ROS) production in rat brain during global perinatal asphyxia: an ESR study. Brain Res. 914, 204-207. doi: 10.1016/s00068993(01)02781-0

Charbaut, E., Curmi, P. A., Ozon, S., Lachkar, S., Redeker, V., and Sobel, A. (2001). Stathmin family proteins display specific molecular and tubulin binding properties. J. Biol. Chem. 276, 16146-16154. doi: 10.1074/jbc.m010637200 
Chen, P., DeWitt, M. R., Bornhorst, J., Soares, F. A., Mukhopadhyay, S., Bowman, A. B., et al. (2014). Age- and manganese-dependent modulation of dopaminergic phenotypes in a C. elegans DJ-1 genetic model of Parkinson's disease. Metallomics doi: 10.1039/c4mt00292j. [Epub ahead of print].

Chen, W., Ji, J., Xu, X., He, S., and Ru, B. (2003). Proteomic comparison between human young and old brains by two-dimensional gel electrophoresis and identification of proteins. Int. J. Dev. Neurosci. 21, 209-216. doi: 10.1016/s07365748(03)00037-6

Chiu, K., Lau, W. M., Lau, H. T., So, K. F., and Chang, R. C. (2007). Microdissection of rat brain for RNA or protein extraction from specific brain region. J. Vis. Exp. 7:269. doi: 10.3791/269

Chugani, H. T., Hovda, D. A., Villablanca, J. R., Phelps, M. E., and Xu, W. F. (1991). Metabolic maturation of the brain: a study of local cerebral glucose utilization in the developing cat. J. Cereb. Blood Flow Metab. 11, 35-47. doi: 10.1038/jcbfm. 1991.4

Cupp, C. J., and Uemura, E. (1980). Age-related changes in prefrontal cortex of Macaca mulatta: quantitative analysis of dendritic branching patterns. Exp. Neurol. 69, 143-163. doi: 10.1016/0014-4886(80)90150-8

da Costa, C. A., Masliah, E., and Checler, F. (2003). Beta-synuclein displays an antiapoptotic p53-dependent phenotype and protects neurons from 6hydroxydopamine-induced caspase 3 activation: cross-talk with alpha-synuclein and implication for Parkinson's disease. J. Biol. Chem. 278, 37330-37335. doi: $10.1074 /$ jbc.m306083200

Dringen, R. (2000). Glutathione metabolism and oxidative stress in neurodegeneration. Eur. J. Biochem. 267:4903. doi: 10.1046/j.1432-1327. 2000.01651.x

Eberling, J. L., Roberts, J. A., De Manincor, D. J., Brennan, K. M., Hanrahan, S. M., Vanbrocklin, H. F., et al. (1995). PET studies of cerebral glucose metabolism in conscious rhesus macaques. Neurobiol. Aging 16, 825-832. doi: 10.1016/01974580(95)00085-s

Eliasson, M. J., Huang, Z., Ferrante, R. J., Sasamata, M., Molliver, M. E., Snyder, S. H., et al. (1999). Neuronal nitric oxide synthase activation and peroxynitrite formation in ischemic stroke linked to neural damage. J. Neurosci. 19, 5910-5918.

Elston, G. N. (2000). Pyramidal cells of the frontal lobe: all the more spinous to think with. J. Neurosci. 20:RC95.

Elston, G. N. (2002). Cortical heterogeneity: implications for visual processing and polysensory integration. J. Neurocytol. 31, 317-335. doi: 10 1023/A:1024182228103

Elston, G. N. (2003). Cortex, cognition and the cell: new insights into the pyramidal neuron and prefrontal function. Cereb. Cortex 13, 1124-1138. doi: 10. 1093/cercor/bhg093

Elston, G. N. (2007). "Specializations in pyramidal cell structure during primate evolution," in Evolution of Nervous Systems, eds J. H. Kaas and T. M. Preuss (Oxford: Academic Press), 191-242.

Elston, G. N., Benavides-Piccione, R., Elston, A., Manger, P. R., and Defelipe, J. (2011a). Pyramidal cells in prefrontal cortex of primates: marked differences in neuronal structure among species. Front. Neuroanat. 5:2. doi: 10.3389/fnana. 2011.00002

Elston, G. N., Benavides-Piccione, R., Elston, A., Zietsch, B., Defelipe, J., Manger, P., et al. (2006a). Specializations of the granular prefrontal cortex of primates: implications for cognitive processing. Anat. Rec. A Discov. Mol. Cell. Evol. Biol. 288, 26-35. doi: 10.1002/ar.a.20278

Elston, G. N., Elston, A., Aurelio-Freire, M., Gomes Leal, W., Dias, I. A., Pereira, A. Jr., et al. (2006b). Specialization of pyramidal cell structure in the visual areas V1, V2 and V3 of the South American rodent, Dasyprocta primnolopha. Brain Res. 1106, 99-110. doi: 10.1016/j.brainres.2006.05.100

Elston, G. N., and Fujita, I. (2014). Pyramidal cell development: postnatal spinogenesis, dendritic growth, axon growth and electrophysiology. Front. Neuroanat. 8:78. doi: 10.3389/fnana.2014.00078

Elston, G. N., and Manger, P. (2014). Pyramidal cells in V1 of African rodents are bigger, more branched and more spiny than those in primates. Front. Neuroanat. 8:4. doi: 10.3389/fnana.2014.00004

Elston, G. N., Oga, T., and Fujita, I. (2009). Spinogenesis and pruning scales across functional hierarchies. J. Neurosci. 29, 3271-3275. doi: 10.1523/JNEUROSCI. 5216-08.2009

Elston, G. N., Oga, T., Okamoto, T., and Fujita, I. (2010a). Spinogenesis and pruning from early visual onset to adulthood: an intracellular injection study of layer III pyramidal cells in the ventral visual cortical pathway of the macaque monkey. Cereb. Cortex 20, 1398-1408. doi: 10.1093/cercor/bhp203

Elston, G. N., Oga, T., Okamoto, T., and Fujita, I. (2011b). Spinogenesis and Pruning in the Anterior ventral Inferotemporal cortex of the Macaque Monkey: an intracellular injection study of layer III pyramidal cells. Front. Neuroanat. 5:42. doi: 10.3389/fnana.2011.00042

Elston, G. N., Okamoto, T., Oga, T., Dornan, D., and Fujita, I. (2010b). Spinogenesis and pruning in the primary auditory cortex of the macaque monkey (Macaca fascicularis): an intracellular injection study of layer III pyramidal cells. Brain Res. 1316, 35-42. doi: 10.1016/j.brainres.2009.12.056

Elston, G. N., and Rockland, K. S. (2002). The pyramidal cell of the sensorimotor cortex of the macaque monkey: phenotypic variation. Cereb. Cortex 12, 1071-1078. doi: 10.1093/cercor/12.10.1071

Elston, G. N., and Rosa, M. G. (1997). The occipitoparietal pathway of the macaque monkey: comparison of pyramidal cell morphology in layer III of functionally related cortical visual areas. Cereb. Cortex 7, 432-452. doi: 10.1093/cercor/ 7.5.432

Elston, G. N., and Rosa, M. G. (1998). Morphological variation of layer III pyramidal neurones in the occipitotemporal pathway of the macaque monkey visual cortex. Cereb. Cortex 8, 278-294. doi: 10.1093/cercor/8.3.278

Elston, G. N., and Rosa, M. G. (2006). Ipsilateral corticocortical projections to the primary and middle temporal visual areas of the primate cerebral cortex: area-specific variations in the morphology of connectionally identified pyramidal cells. Eur. J. Neurosci. 23, 3337-3345. doi: 10.1111/j.1460-9568.2006. 04847.x

Elston, G. N., Rosa, M. G., and Calford, M. B. (1996). Comparison of dendritic fields of layer III pyramidal neurons in striate and extrastriate visual areas of the marmoset: a Lucifer yellow intracellular injection. Cereb. Cortex 6, 807-813. doi: 10.1093/cercor/6.6.807

Finnegan, S., Robson, J. L., Wylie, M., Healy, A., Stitt, A. W., and Curry, W. J. (2008). Protein expression profiling during chick retinal maturation: a proteomicsbased approach. Proteome Sci. 6:34. doi: 10.1186/1477-5956-6-34

Fraser, H. B., Khaitovich, P., Plotkin, J. B., Pääbo, S., and Eisen, M. B. (2005). Aging and gene expression in the primate brain. PLoS Biol. 3:e274. doi: 10 . 1371/journal.pbio.0030274

Geschwind, D. H., and Rakic, P. (2013). Cortical evolution: judge the brain by its cover. Neuron 80, 633-647. doi: 10.1016/j.neuron.2013.10.045

Haniu, H., Komori, N., Takemori, N., Singh, A., Ash, J. D., and Matsumoto, H. (2006). Proteomic trajectory mapping of biological transformation: application to developmental mouse retina. Proteomics 6, 3251-3261. doi: 10.1002/pmic. 200500813

Hashimoto, M., Bar-On, P., Ho, G., Takenouchi, T., Rockenstein, E., Crews, L., et al. (2004). Beta-synuclein regulates Akt activity in neuronal cells. A possible mechanism for neuroprotection in Parkinson's disease. J. Biol. Chem. 279, 23622-23629. doi: 10.1074/jbc.m313784200

Hashimoto, M., Rockenstein, E., Mante, M., Mallory, M., and Masliah, E. (2001) $\beta$-Synuclein inhibits alpha-synuclein aggregation: a possible role as an antiparkinsonian factor. Neuron 32, 213-223. doi: 10.1016/S0896-6273(01)00462-7

Hayashi, K., Pan, Y., Shu, H., Ohshima, T., Kansy, J. W., White, C. L., et al. (2006). Phosphorylation of the tubulin-binding protein, stathmin, by Cdk5 and MAP kinases in the brain. J. Neurochem. 99, 237-250. doi: 10.1111/j.1471-4159.2006. 04113.x

He, X., Zhang, X. M., Wu, J., Fu, J., Mou, L., Lu, D. H., et al. (2014). Olfactory experience modulates immature neuron development in postnatal and adult guinea pig piriform cortex. Neuroscience 259, 101-112. doi: 10.1016/j. neuroscience.2013.11.056

Heumann, D., and Leuba, G. (1983). Neuronal death in the development and aging of the cerebral cortex of the mouse. Neuropathol. Appl. Neurobiol. 9, 297-311. doi: 10.1111/j.1365-2990.1983.tb00116.x

Heumann, D., Leuba, G., and Rabinowicz, T. (1978). Postnatal development of the mouse cerebral neocortex. IV. Evolution of the total cortical volume, of the population of neurons and glial cells. J. Hirnforsch. 19, 385-393.

Hod, Y., Pentyala, S. N., Whyard, T. C., and El-Maghrabi, M. R. (1999). Identification and characterization of a novel protein that regulates RNAprotein interaction. J. Cell. Biochem. 72, 435-444. doi: 10.1002/(sici)10974644(19990301)72:3<435::aid-jcb12>3.3.co;2-8

Hua, T., Li, X., He, L., Zhou, Y., Wang, Y., and Leventhal, A. G. (2006). Functional degradation of visual cortical cells in old cats. Neurobiol. Aging 27, 155-162. doi: 10.1016/j.neurobiolaging.2004.11.012 
Huttenlocher, P. R. (1990). Morphometric study of human cerebral cortex development. Neuropsychologia 28, 517-527. doi: 10.1016/0028-3932(90) 90031-i

Huttenlocher, P. R., and Dabholkar, A. S. (1997). Regional differences in synaptogenesis in human cerebral cortex. J. Comp. Neurol. 387, 167-178. doi: 10. 1002/(sici)1096-9861(19971020)387:2<167::aid-cnel>3.0.co;2-z

Huttenlocher, P. R., de Courten, C., Garey, L. J., and Van der Loos, H. (1982). Synaptogenesis in human visual cortex-evidence for synapse elimination during normal development. Neurosci. Lett. 33, 247-252. doi: 10.1016/03043940(82)90379-2

Imamoto, K., and Leblond, C. P. (1978). Radioautographic investigation of gliogenesis in the corpus callosum of young rats. II. Origin of microglial cells. J. Comp. Neurol. 180, 139-163. doi: 10.1002/cne.901800109

Jacobs, B., Driscoll, L., and Schall, M. (1997). Life-span dendritic and spine changes in areas 10 and 18 of human cortex: a quantitative Golgi study. J. Comp. Neurol. 386, 661-680. doi: 10.1002/(sici)1096-9861(19971006)386:4<661::aidcne11>3.3.co;2-4

Jacobs, B., Schall, M., Prather, M., Kapler, E., Driscoll, L., Baca, S., et al. (2001). Regional dendritic and spine variation in human cerebral cortex: a quantitative golgi study. Cereb. Cortex 11, 558-571. doi: 10.1093/cercor/11. 6.558

Jacobs, B., and Scheibel, A. B. (2002). "Regional dendritic variation in primate cortical pyramidal cells," in Cortical Areas: Unity And Diversity, eds A. Schüz and R. Miller (London: Taylor and Francis), 111-131.

Jim, D. Y., and Jeang, K. T. (1999). "Peroxiredoxin in cell signaling and HIV infection," in Antioxidants and Redox Regulation of Genes, eds C. K. Sen, H. Sies and P. A. Baeuerle (New York: Academic Press), 381-407.

Kasper, E. M., Larkman, A. U., Lubke, J., and Blakemore, C. (1994). Pyramidal neurons in layer 5 of the rat visual cortex. I. Correlation among cell morphology, intrinsic electrophysiological properties and axon targets. J. Comp. Neurol. 339, 459-474. doi: 10.1002/cne.903390402

Kim, S. H., Fountoulakis, M., Cairns, N., and Lubec, G. (2001). Protein levels of human peroxiredoxin subtypes in brains of patients with Alzheimer's disease and down syndrome. J. Neural Transm. Suppl. 61, 223-235. doi: 10.1007/978-37091-6262-0_18

Kim, S. U., Jin, M. H., Kim, Y. S., Lee, S. H., Cho, Y. S., Cho, K. J., et al. (2011). Peroxiredoxin II preserves cognitive function against age-linked hippocampal oxidative damage. Neurobiol. Aging 32, 1054-1068. doi: 10.1016/ j.neurobiolaging.2009.05.017

Kim, C. B., Tom, B. W., and Spear, P. D. (1996). Effects of aging on the densities, numbers and sizes of retinal ganglion cells in rhesus monkey. Neurobiol. Aging 17, 431-438. doi: 10.1016/0197-4580(96)00038-3

Kline, D. W., Schieber, F., Abusamra, L. C., and Coyne, A. C. (1983). Age, the eye and the visual channels: contrast sensitivity and response speed. J. Gerontol. 38, 211-216. doi: 10.1093/geronj/38.2.211

Krapfenbauer, K., Engidawork, E., Cairns, N., Fountoulakis, M., and Lubec, G. (2003). Aberrant expression of peroxiredoxin subtypes in neurodegenerative disorders. Brain Res. 967, 152-160. doi: 10.1016/s0006-8993(02)04243-9

Lassmann, H., and van Horssen, J. (2011). The molecular basis of neurodegeneration in multiple sclerosis. FEBS Lett. 585, 3715-3723. doi: 10. 1016/j.febslet.2011.08.004

Lee, C. K., Weindruch, R., and Prolla, T. A. (2000). Gene-expression profile of the ageing brain in mice. Nat. Genet. 25, 294-297. doi: 10.1038/77046

Liang, Z., Li, H., Yang, Y., Li, G., Tang, Y., Bao, P., et al. (2012). Selective effects of aging on simple and complex cells in primary visual cortex of rhesus monkeys. Brain Res. 1470, 17-23. doi: 10.1016/j.brainres.2012.06.017

Ling, E. A. (1976). Some aspects of amoeboid microglia in the corpus callosum and neighbouring regions of neonatal rats. J. Anat. 121(Pt. 1), 29-45.

Liu, W., Brosnan, C. F., Dickson, D. W., and Lee, S. C. (1994). Macrophage colonystimulating factor mediates astrocyte-induced microglial ramification in human fetal central nervous system culture. Am. J. Pathol. 145, 48-53.

Liu, F., Nguyen, J. L., Hulleman, J. D., Li, L., and Rochet, J. C. (2008). Mechanisms of DJ-1 neuroprotection in a cellular model of Parkinson's disease. J. Neurochem. 105, 2435-2453. doi: 10.1111/j.1471-4159.2008.05333.x

Loerch, P. M., Lu, T., Dakin, K. A., Vann, J. M., Isaacs, A., Geula, C., et al. (2008). Evolution of the aging brain transcriptome and synaptic regulation. PLoS One 3:e3329. doi: 10.1371/journal.pone.0003329

López-Hidalgo, M., and Schummers, J. (2014). Cortical maps: a role for astrocytes? Curr. Opin. Neurobiol. 24, 176-189. doi: 10.1016/j.conb.2013.11.001
Luebke, J. I., Medalla, M., Amatrudo, J. M., Weaver, C. M., Crimins, J. L., Hunt, B., et al. (2013). Age-related changes to layer 3 pyramidal cells in the rhesus monkey visual cortex. Cereb. Cortex doi: 10.1093/cercor/bht336. [Epub ahead of print].

Matsubara, J. A., Chase, R., and Thejomayen, M. (1996). Comparative morphology of three types of projection-identified pyramidal neurons in the superficial layers of cat visual cortex. J. Comp. Neurol. 366, 93-108. doi: 10.1002/(sici)10969861(19960226)366:1<93::aid-cne7>3.3.co;2-h

Mattson, M. P., and Magnus, T. (2006). Ageing and neuronal vulnerability. Nat Rev. Neurosci. 7, 278-294. doi: 10.1038/nrn1886

Mavroudis, I., Petrides, F., Manani, M., Theocharides, C., Ciobica, A., Padurariu, M., et al. (2012). Dendritic and spinal alterations of the spiny stellate cells of the human visual cortex during normal aging. Folia Neuropathol. 50, 261-269. doi: $10.5114 /$ fn.2012.30526

McCormick, D. A., and Prince, D. A. (1987). Post-natal development of electrophysiological properties of rat cerebral cortical pyramidal neurones. $J$. Physiol. 393, 743-762. doi: 10.1113/jphysiol.1987.sp016851

Metherate, R., and Aramakis, V. B. (1999). Intrinsic electrophysiology of neurons in thalamorecipient layers of developing rat auditory cortex. Brain Res. Dev. Brain Res. 2115, 131-144. doi: 10.1016/s0165-3806(99)00058-9

Mizusawa, H., Ishii, T., and Bannai, S. (2000). Peroxiredoxin I (macrophage 23 kDa stress protein) is highly and widely expressed in the rat nervous system. Neurosci. Lett. 283, 57-60. doi: 10.1016/s0304-3940(00)00910-1

Moore, D. J., West, A. B., Dawson, V. L., and Dawson, T. M. (2005). Molecular pathophysiology of Parkinson's disease. Annu. Rev. Neurosci. 28, 57-87. doi: 10. 1146/annurev.neuro.28.061604.135718

Moreira, P. I., Honda, K., Liu, Q., Santos, M. S., Oliveira, C. R., Aliev, G., et al. (2005). Oxidative stress: the old enemy in Alzheimer's disease pathophysiology. Curr. Alzheimer Res. 2, 403-408. doi: 10.2174/156720505774330537

Mori, S., and Leblond, C. P. (1969). Identification of microglia in light and electron microscopy. J. Comp. Neurol. 135, 57-80. doi: 10.1002/cne.901350104

Mori, N., and Morii, H. (2002). SCG10-related neuronal growth-associated proteins in neural development, plasticity, degeneration and aging. J. Neurosci. Res. 70, 264-273. doi: 10.1002/jnr.10353

Morrison, J. H., and Hof, P. R. (1997). Life and death of neurons in the aging brain. Science 278, 412-419. doi: 10.1126/science.278.5337.412

Mullett, S. J., Hamilton, R. L., and Hinkle, D. A. (2009). DJ-1 immunoreactivity in human brain astrocytes is dependent on infarct presence and infarct age. Neuropathology 29, 125-131. doi: 10.1111/j.1440-1789.2008.00955.x

Mullett, S. J., and Hinkle, D. A. (2009). DJ-1 knock-down in astrocytes impairs astrocyte-mediated neuroprotection against rotenone. Neurobiol. Dis. 22, 28-36. doi: 10.1016/j.nbd.2008.09.013

Mullett, S. J., and Hinkle, D. A. (2011). DJ-1 deficiency in astrocytes selectively enhances mitochondrial complex I inhibitor-induced neurotoxicity. J. Neurochem. 117, 375-387. doi: 10.1111/j.1471-4159.2011.07175.x

Murayama, Y., Fujita, I., and Kato, M. (1997). Contrasting forms of synaptic plasticity in monkey inferotemporal and primary visual cortices. Neuroreport 8, 1503-1508. doi: 10.1097/00001756-199704140-00036

Nadeau, S., and Rivest, S. (2000). Role of microglial-derived tumor necrosis factor in mediating CD14 transcription and nuclear factor kappa B activity in the brain during endotoxemia. J. Neurosci. 20, 3456-3468.

Nagakubo, D., Taira, T., Kitaura, H., Ikeda, M., Tamai, K., Iguchi-Ariga, S. M., et al. (1997). DJ-1, a novel oncogene which transforms mouse NIH3T3 cells in cooperation with ras. Biochem. Biophys. Res. Commun. 231, 509-513. doi: 10. 1006/bbrc.1997.6132

Nakazawa, T., Nakano, I., Furuyama, T., Morii, H., Tamai, M., and Mori, N. (2000). The SCG10-related gene family in the developing rat retina: persistent expression of SCLIP and stathmin in mature ganglion cell layer. Brain Res. 861, 399-407. doi: 10.1016/s0006-8993(00)02056-4

Nandy, K. (1981). Morphological changes in the cerebellar cortex of aging Macaca nemestrina. Neurobiol. Aging 2, 61-64. doi: 10.1016/0197-4580(81) 90061-0

Nelson, T. J., Backlund, P. S. Jr., and Alkon, D. L. (2004). Hippocampal proteinprotein interactions in spatial memory. Hippocampus 14, 46-57. doi: 10 1002/hipo.10152

Neumann, M., Müller, V., Görner, K., Kretzschmar, H. A., Haass, C., and Kahle, P. J. (2004). Pathological properties of the Parkinson's disease-associated protein DJ-1 in alpha-synucleinopathies and tauopathies: relevance for multiple system atrophy and Pick's disease. Acta Neuropathol. 107, 489-496. doi: 10. 1007/s00401-004-0834-2 
Nomura, H., Ando, F., Niino, N., Shimokata, H., and Miyake, Y. (2003). Age-related change in contrast sensitivity among Japanese adults. Jpn. J. Ophthalmol. 47, 299-303. doi: 10.1016/s0021-5155(03)00011-x

Oga, T., Aoi, H., Sasaki, T., Fujita, I., and Ichinohe, N. (2013). Postnatal development of layer III pyramidal cells in the primary visual, inferior temporal and prefrontal cortices of the marmoset. Front. Neural Circuits 7:31. doi: 10. 3389/fncir.2013.00031

Olzmann, J. A., Bordelon, J. R., Muly, E. C., Rees, H. D., Levey, A. I., Li, L., et al. (2007). Selective enrichment of DJ-1 protein in primate striatal neuronal processes: implications for Parkinson's disease. J. Comp. Neurol. 500, 585-599. doi: $10.1002 /$ cne. 21191

Oswald, A. M., and Reyes, A. D. (2008). Maturation of intrinsic and synaptic properties of layer $2 / 3$ pyramidal neurons in mouse auditory cortex. $J$. Neurophysiol. 99, 2998-3008. doi: 10.1152/jn.01160.2007

Ozon, S., El Mestikawy, S., and Sobel, A. (1999). Differential, regional and cellular expression of the stathmin family transcripts in the adult rat brain. J. Neurosci. Res. 56, 553-564. doi: 10.1002/(sici)1097-4547(19990601)56:5<553::aidjnr11>3.3.co; $2-\mathrm{a}$

Pakkenberg, B., and Gundersen, H. J. (1997). Neocortical neuron number in humans: effect of sex and age. J. Comp. Neurol. 384, 312-320. doi: 10. 1002/(sici)1096-9861(19970728)384:2<312::aid-cne10>3.3.co;2-g

Palkovits, M., and Brownstein, M. J. (1988). Maps and Guide to Microdissection of the Rat Brain. New York: Elsevier.

Park, J. Y., and Lansbury, P. T. Jr. (2003). Beta-synuclein inhibits formation of alphasynuclein protofibrils: a possible therapeutic strategy against Parkinson's disease. Biochemistry 42, 3696-3700. doi: 10.1021/bi020604a

Park, D. C., Polk, T. A., Park, R., Minear, M., Savage, A., and Smith, M. R. (2004). Aging reduces neural specialization in ventral visual cortex. Proc. Natl. Acad. Sci. U S A 101, 13091-13095. doi: 10.1073/pnas.0405148101

Peters, A., Leahu, D., Moss, M. B., and McNally, K. J. (1994). The effects of aging on area 46 of the frontal cortex of the rhesus monkey. Cereb. Cortex 4, 621-635. doi: 10.1093/cercor/4.6.621

Petrovic, V., Costa, R. H., Lau, L. F., Raychaudhuri, P., and Tyner, A. L. (2008). FoxM1 regulates growth factor-induced expression of kinase-interacting stathmin (KIS) to promote cell cycle progression. J. Biol. Chem. 283, 453-460. doi: 10.1074/jbc.m705792200

Prewitt, C. M., Niesman, I. R., Kane, C. J., and Houlé, J. D. (1997). Activated macrophage/microglial cells can promote the regeneration of sensory axons into the injured spinal cord. Exp. Neurol. 148, 433-443. doi: 10.1006/exnr.1997.6694

Primiani, C. T., Ryan, V. H., Rao, J. S., Cam, M. C., Ahn, K., Modi, H. R., et al. (2014). Coordinated gene expression of neuroinflammatory and cell signaling markers in dorsolateral prefrontal cortex during human brain development and aging. PLoS One 9:e110972. doi: 10.1371/journal.pone.0110972

Rakic, P., Bourgeois, J. P., and Goldman-Rakic, P. S. (1994). Synaptic development of the cerebral cortex: implications for learning, memory and mental illness. Prog. Brain Res. 102, 227-243. doi: 10.1016/s0079-6123(08)60543-9

Rizzu, P., Hinkle, D. A., Zhukareva, V., Bonifati, V., Severijnen, L. A., Martinez, D., et al. (2004). DJ-1 colocalizes with tau inclusions: a link between parkinsonism and dementia. Ann. Neurol. 55, 113-118. doi: 10.1002/ana.10782

Rochefort, N., Quenech'du, N., Watroba, L., Mallat, M., Giaume, C., and Milleret, C. (2002). Microglia and astrocytes may participate in the shaping of visual callosal projections during postnatal development. J. Physiol. Paris 96, 183-192. doi: 10.1016/s0928-4257(02)00005-0

Rodríguez, V. M., Del Razo, L. M., Limón-Pacheco, J. H., Giordano, M., SánchezPeña, L. C., Uribe-Querol, E., et al. (2005). Glutathione reductase inhibition and methylated arsenic distribution in Cd1 mice brain and liver. Toxicol. Sci. 84, 157-166. doi: 10.1093/toxsci/kfi057

Roland, P. E. (1984). Metabolic measurements of the working frontal cortex in man. Trends Neurosci. 7, 430-435. doi: 10.1016/s0166-2236(84)80148-4

Romand, S., Wang, Y., Toledo-Rodriguez, M., and Markram, H. (2011). Morphological development of thick-tufted layer v pyramidal cells in the rat somatosensory cortex. Front. Neuroanat. 5:5. doi: 10.3389/fnana.2011.00005

Ross, J. E., Clarke, D. D., and Bron, A. J. (1985). Effect of age on contrast sensitivity function: uniocular and binocular findings. Br. J. Ophthalmol. 69, 51-56. doi: 10 . 1136/bjo.69.1.51

Sarafian, T. A., Verity, M. A., Vinters, H. V., Shih, C. C., Shi, L., Ji, X. D., et al. (1999). Differential expression of peroxiredoxin subtypes in human brain cell types. J. Neurosci. Res. 56, 206-212. doi: 10.1002/(sici)10974547(19990415)56:2<206::aid-jnr10>3.0.co;2-x
Sasaki, T., Aoi, H., Oga, T., Fujita, I., and Ichinohe, N. (2014). Postnatal development of dendritic structure of layer III pyramidal neurons in the medial prefrontal cortex of marmoset. Brain Struct. Funct. doi: 10.1007/s00429-0140853-2. [Epub ahead of print].

Satorre, J., Cano, J., and Reinoso-Suárez, F. (1985). Stability of the neuronal population of the dorsal lateral geniculate nucleus (LGNd) of aged rats. Brain Res. 339, 375-377. doi: 10.1016/0006-8993(85)90108-8

Schefrin, B. E., Tregear, S. J., Harvey, L. O. Jr., and Werner, J. S. (1999). Senescent changes in scotopic contrast sensitivity. Vision Res. 39, 3728-3736. doi: 10. 1016/s0042-6989(99)00072-3

Schmolesky, M. T., Wang, Y., Pu, M., and Leventhal, A. G. (2000). Degradation of stimulus selectivity of visual cortical cells in senescent rhesus monkeys. Nat. Neurosci. 3, 384-390. doi: 10.1038/73957

Schubart, U. K., Yu, J., Amat, J. A., Wang, Z., Hoffmann, M. K., and Edelmann, W. (1996). Normal development of mice lacking metablastin (P19), a phosphoprotein implicated in cell cycle regulation. J. Biol. Chem. 271, 14062-14066. doi: 10.1074/jbc.271.24.14062

Shen, A., Liu, Y., Zhao, J., Qin, J., Shi, S., Chen, M., et al. (2008). Temporal-spatial expressions of p27kipl and its phosphorylation on Serine-10 after acute spinal cord injury in adult rat: implications for post-traumatic glial proliferation. Neurochem. Int. 52, 1266-1275. doi: 10.1016/j.neuint.2008.01.011

Shu, T., and Richards, L. J. (2001). Cortical axon guidance by the glial wedge during the development of the corpus callosum. J. Neurosci. 21, 2749-2758.

Singh, A. K., and Shichi, H. (2001). Peroxiredoxin in bovine ocular tissues: immunohistochemical localization and in situ hybridization. J. Ocul. Pharmacol. Ther. 17, 279-286. doi: 10.1089/108076801750295308

Singh, I. N., Sullivan, P. G., Deng, Y., Mbye, L. H., and Hall, E. D. (2006). Time course of post-traumatic mitochondrial oxidative damage and dysfunction in a mouse model of focal traumatic brain injury: implications for neuroprotective therapy. J. Cereb. Blood Flow Metab. 26, 1407-1418. doi: 10.1038/sj.jcbfm. 9600297

Singh, A. K., Tiwari, M. N., Dixit, A., Upadhyay, G., Patel, D. K., Singh, D., et al. (2011). Nigrostriatal proteomics of cypermethrin-induced dopaminergic neurodegeneration: microglial activation-dependent and -independent regulations. Toxicol. Sci. 122, 526-538. doi: 10.1093/toxsci/kfr115

Sobel, A. (1991). Stathmin: a relay phosphoprotein for multiple signal transduction? Trends Biochem. Sci. 16, 301-305. doi: 10.1016/09680004(91)90123-d

Spillantini, M. G., Schmidt, M. L., Lee, V. M., Trojanowski, J. Q., Jakes, R., and Goedert, M. (1997). Alpha-synuclein in Lewy bodies. Nature 388, 839-840. doi: $10.1038 / 42166$

Spruston, N. (2008). Pyramidal neurons: dendritic structure and synaptic integration. Nat. Rev. Neurosci. 9, 206-221. doi: 10.1038/nrn2286

Stevens, B. (2008). Neuron-astrocyte signaling in the development and plasticity of neural circuits. Neurosignals 16, 278-288. doi: 10.1159/000123038

Stranahan, A. M., Jiam, N. T., Spiegel, A. M., and Gallagher, M. (2012). Aging reduces total neuron number in the dorsal component of the rodent prefrontal cortex. J. Comp. Neurol. 520, 1318-1326. doi: 10.1002/cne.22790

Sung, Y. H., and Eliezer, D. (2007). Residual structure, backbone dynamics and interactions within the synuclein family. J. Mol. Biol. 372, 689-707. doi: 10. 1016/j.jmb.2007.07.008

Swanson, L. W. (1992). Brain Maps: Structure of the Rat Brain. Amsterdam: Elsevier. Torreilles, F., Salman-Tabcheh, S., Guérin, M., and Torreilles, J. (1999). Neurodegenerative disorders: the role of peroxynitrite. Brain Res. Brain Res. Rev. 30, 153-163. doi: 10.1016/s0165-0173(99)00014-4

Trudler, D., Weinreb, O., Mandel, S. A., Youdim, M. B., and Frenkel, D. (2014). DJ-1 deficiency triggers microglia sensitivity to dopamine toward a pro-inflammatory phenotype that is attenuated by rasagiline. J. Neurochem. 129, 434-447. doi: 10 . $1111 /$ jnc. 12633

Tsigelny, I. F., Bar-On, P., Sharikov, Y., Crews, L., Hashimoto, M., Miller, M. A., et al. (2007). Dynamics of alpha-synuclein aggregation and inhibition of porelike oligomer development by beta-synuclein. FEBS J. 274, 1862-1877. doi: 10. 1111/j.1742-4658.2007.05733.x

van Horssen, J., Witte, M. E., Schreibelt, G., and de Vries, H. E. (2011). Radical changes in multiple sclerosis pathogenesis. Biochim. Biophys. Acta 1812, 141150. doi: 10.1016/j.bbadis.2010.06.011

Vercelli, A., and Innocenti, G. M. (1993). Morphology of visual callosal neurons with different locations, contralateral targets or patterns of development. Exp. Brain Res. 94, 393-404. doi: 10.1007/bf00230198 
Wang, X., Phelan, S. A., Forsman-Semb, K., Taylor, E. F., Petros, C., Brown, A., et al. (2003). Mice with targeted mutation of peroxiredoxin 6 develop normally but are susceptible to oxidative stress. J. Biol. Chem. 278, 25179-25190. doi: 10. 1074/jbc.m302706200

Wang, H., Xie, X., Li, X., Chen, B., and Zhou, Y. (2006). Functional degradation of visual cortical cells in aged rats. Brain Res. 1122, 93-98. doi: 10.1016/j.brainres. 2006.09.010

Weale, R. A. (1975). Senile changes in visual acuity. Trans. Ophthalmol. Soc. U K 95 , 36-38.

Wilhelmus, M. M., Nijland, P. G., Drukarch, B., de Vries, H. E., and van Horssen, J. (2012). Involvement and interplay of Parkin, PINK1 and DJ1 in neurodegenerative and neuroinflammatory disorders. Free Radic. Biol. Med. 53, 983-992. doi: 10.1016/j.freeradbiomed.2012.05.040

Woolsey, T. A., and Van der Loos, H. (1970). The structural organization of layer IV in the somatosensory region (SI) of mouse cerebral cortex. The description of a cortical field composed of discrete cytoarchitectonic units. Brain Res. 17, 205-242. doi: 10.1016/0006-8993(70)90079-x

Woolsey, T. A., Welker, C., and Schwartz, R. H. (1975). Comparative anatomical studies of the SmL face cortex with special reference to the occurrence of "barrels" in layer IV. J. Comp. Neurol. 164, 79-94. doi: 10.1002/cne.901640107

Yankner, B. A., Lu, T., and Loerch, P. (2008). The aging brain. Annu. Rev. Pathol. 3, 41-66. doi: 10.1146/annurev.pathmechdis.2.010506.092044
Zhang, Z. W. (2004). Maturation of layer V pyramidal neurons in the rat prefrontal cortex: intrinsic properties and synaptic function. J. Neurophysiol. 91, 1171-1182. doi: 10.1152/jn.00855.2003

Conflict of Interest Statement: The authors declare that the research was conducted in the absence of any commercial or financial relationships that could be construed as a potential conflict of interest.

Received: 23 October 2014; accepted: 04 February 2015; published online: 04 March 2015.

Citation: Böhm MRR, Melkonyan H and Thanos S (2015) Life-time expression of the proteins peroxiredoxin, beta-synuclein, PARK7/DJ-1, and stathmin in the primary visual and primary somatosensory cortices in rats. Front. Neuroanat. 9:16. doi: $10.3389 /$ fnana.2015.00016

This article was submitted to the journal Frontiers in Neuroanatomy.

Copyright (c) 2015 Böhm, Melkonyan and Thanos. This is an open-access article distributed under the terms of the Creative Commons Attribution License (CC BY). The use, distribution and reproduction in other forums is permitted, provided the original author(s) or licensor are credited and that the original publication in this journal is cited, in accordance with accepted academic practice. No use, distribution or reproduction is permitted which does not comply with these terms. 